\title{
A Bacterial Protein Targets the BAHD1 Chromatin Complex to Stimulate Type III Interferon Response
}

Alice Lebreton1,2,3, Goran Lakisic4, Viviana Job5, Lauriane Fritsch6, To Nam Tham1,2,3, Ana Camejo7, Pierre-Jean Matteï5, Béatrice Regnaults, Marie-Anne Nahori1,2,3, Didier Cabanes7, Alexis Gautreau4, Slimane Ait-Si-Ali6, Andréa Dessen5,

Pascale Cossart1,2,3* and Hélène Bierne1,2,3*

1. Institut Pasteur, Unité des Interactions Bactéries Cellules, Paris, F-75015 France;

2. Inserm, U604, Paris, F-75015 France;

3. INRA, USC2020, Paris, F-75015 France.

4. CNRS UPR3082, Laboratoire d'Enzymologie et de Biochimie Structurales, Gif-sur-Yvette, F-91198 France.

5. Institut de Biologie Structurale, Bacterial Pathogenesis Group, UMR 5075 (CNRS/CEA/UJF), Grenoble, France.

6. CNRS UMR7216, Université Paris 7 Diderot, Paris, F-75013 France.

7. Institute for Molecular and Cell Biology, Porto, Portugal.

8. Institut Pasteur, Génopole, Paris, F-75015 France.

* To whom correspondence should be addressed. helene.bierne@inrae.fr; pascale.cossart@pasteur.fr

This is a post-print version of an article published by the American Association for the Advancement of Science in Science in March 2011, available online as doi:10.1126/science. 1200120

\section{One-sentence summary}

A virulence factor secreted by Listeria monocytogenes alleviates BAHD1-mediated silencing of interferon- $\lambda$ stimulated genes.

\begin{abstract}
Intracellular pathogens such as Listeria monocytogenes subvert cellular functions through the interaction of bacterial effectors with host components. Here we found that a secreted listerial virulence factor, LntA, could target the chromatin repressor BAHD1 in the host cell nucleus to activate IFN-stimulated genes (ISGs). IFN- $\lambda$ expression was induced in response to infection of epithelial cells with bacteria lacking LntA; however, the BAHD1-chromatin associated complex repressed downstream ISGs. In contrast, in cells infected with $\ln t A$ expressing bacteria, LntA prevented BAHD1 recruitment to ISGs and stimulated their expression. Murine listeriosis decreased in $B A H D 1+$ - mice or when $\ln t A$ was constitutively expressed. Thus the LntA-BAHD1 interplay may modulate IFN- $\lambda$-mediated immune response to control bacterial colonization of the host.
\end{abstract}


Listeria monocytogenes is a food-borne pathogen that can cause serious illness in pregnant women and immunocompromised individuals (1). This intracellular bacterium uses an arsenal of effectors to exploit cellular functions in various ways (2). Host cells respond to this invasion by turning on appropriate defense transcriptional programs (3). Listeria and other pathogens can manipulate chromatin to reprogram host transcription $(4,5)$. However, very few bacterial molecules have been shown to enter eukaryotic cell nuclei, and knowledge about microbial factors that may act directly on the chromatin-regulatory machinery is limited (6).

To identify factors involved in bacterial pathogenicity, we screened the L. monocytogenes strain EGDe genome for genes encoding secreted proteins absent in non-pathogenic Listeria species. lmo0438/lntA (listeria nuclear targeted protein $A$ ) was one such gene (fig. S1A). IntA was expressed at very low levels by the EGDe strain grown in brain-heart infusion (BHI) medium (fig. S1B, 7). Two major regulators of virulence genes, PrfA and $\sigma \mathrm{B}$, were required for basal $\ln t A$ transcription (fig. 1A). $\ln t A$ expression was significantly higher in bacteria harvested from spleens of infected mice $48 \mathrm{~h}$ after intravenous inoculation, compared to bacteria grown in BHI (fig. 1B). In addition, deletion of $\operatorname{lnt} A$ led to a decrease in bacterial colonization of spleens and livers, as well as blood bacteraemia (fig. 1B). $\ln t A$ thus contributes to $L$. monocytogenes virulence. It encodes a 205 -amino acid basic protein with a $\mathrm{N}$-terminal signal peptide but no sequence similarity with any known polypeptide. The $2.3 \AA$ resolution structure of LntA reveals a compact $\alpha$-helical fold (fig. S2, PDB ID\#2x14). Consistent with low lntA transcription levels in vitro, LntA was undetectable in either total extracts or supernatants of wild type (WT) bacteria grown in BHI (fig. 1C).

To address the role of LntA during L. monocytogenes cellular infection, we generated strains that constitutively expressed $\ln t A$ under the control of a heterologous promoter, either on the chromosome $\left(\ln t A_{\mathrm{c}^{+}}\right)$or on a plasmid in fusion with the V5 tag (lntAv5+) (tables S1, S2). Both strains produced and secreted LntA (fig. 1C and S1C), and showed no noticeable difference in entry or multiplication in cultured cells compared to the WT or $\ln t A$-deficient strains $(\Delta \ln t A$, $\ln t A$ - or $\ln t A_{\mathrm{c}-}$ ) (table S3A, fig. S3). Secreted LntA accumulated in the nucleus of fibroblasts after $22 \mathrm{~h}$ of infection with $l n t A \mathrm{v} 5+$ bacteria (fig. 1D and S4A). We thus assessed whether LntA interacted with nuclear proteins in a large-scale yeast two-hybrid screen of a human cDNA library. One of the strongest LntA interactors was BAHD1, a silencing factor that orchestrates heterochromatin assembly at specific genes such as $I G F 2$ (8). A fusion of LntA with glutathione-S-transferase (GST) pulled down V5-tagged BAHD1 from nuclear extracts, confirming the capacity of LntA to specifically interact with BAHD1 (fig. 1E). When produced ectopically in human fibroblasts, LntA co-localized with BAHD1-YFP-induced heterochromatin nuclear foci (8), both in fixed (LntA-V5, fig. 1F) and in living cells (LntACFP, fig. S4B).

Because BAHD1 is involved in gene silencing, LntA might control host gene expression. To assess this hypothesis, we performed a transcriptome analysis of LoVo epithelial cells infected for $24 \mathrm{~h}$ either with $\ln t A \mathrm{v} 5+$ or $\ln t A-$ bacteria (GEO database, GSE26414). The $\ln t A \mathrm{v} 5+$ bacteria specifically up-regulated the expression of a subset of genes, out of which 39 displayed more than a 2-fold induction (table S4). $83 \%$ of these genes belonged to the interferon-inducible genes regulon: 28 are known ISGs, including 3 genes (IL29, IL28A and IL28B) that encode type III interferons (IFN $-\lambda 1,-\lambda 2$ and $-\lambda 3$ ), and 4 are predicted ISGs. LntA may thus play a role in the IFN-III-mediated immune response. This pathway controls various viral infections, especially in epithelial tissues (9-13).

We confirmed that WT L. monocytogenes triggered the expression of IFN- $\lambda 2$ in intestinal LoVo and placental JEG-3 epithelial cells (fig. $2 \mathrm{~A}$; fig. S5A); type I IFN- $\beta 1$ was also induced, but type II $I F N-\gamma$ was undetectable. However, the induction of downstream ISGs was modest 
(fig. 2A), except for $C C L 5$, which, like $I F N-\lambda$ genes, is controlled both by NF- $\kappa \mathrm{B}$ and IRFs (fig. S9, 14). These data suggested that interferon signaling was down-regulated in infected cells. We wondered whether the host factor BAHD1 could act as a repressor of ISGs, as it does for $I G F 2$ (fig. S4B, 8). Knockdown of BAHD1 had no or minor effect on ISG expression in non-infected LoVo cells (fig. 2B). However, infection of these BAHD1-depleted cells with L. monocytogenes induced the expression of several ISGs, highlighting that BAHD1 could act as a negative regulator of this pathway upon bacterial-triggered signaling (fig. 2B, S5B).

ISG expression is governed by IRF/STAT transcriptional activators and by chromatin structure regulators. Except for HP1 proteins, found as BAHD1 partners (8) and repressing ISGs (15), there is no reported link between BAHD1 and STAT signaling. To address whether BAHD1 was associated with other proteins involved in ISG regulation, we purified the BAHD1-associated complex from the chromatin fraction of HEK293 cells expressing His6Protein C-tagged BAHD1 (HPT-BAHD1) by tandem affinity chromatography (fig. 2C, S6). Mass spectrometry analysis of the complex revealed several polypeptides involved in chromatin and transcriptional regulation, including KAP1, HP1 $\gamma$ and histone deacetylases HDAC1/2, as confirmed by immunoblots (fig. 2C). HDAC1/2 directly binds STAT (16), as does the scaffolding protein KAP1, which represses both basal and IFN-I-mediated STATdriven transcription $(17,18)$. We investigated whether KAP1 also repressed ISGs during infection with Listeria. KAPI knockdown induced ISG expression in non-infected cells, and bacterial infection greatly enhanced this induction (fig. 2B, S5C). The BAHD1/KAP1corepressor complex thus inhibits ISGs downstream of IFN-III stimulation during L. monocytogenes infection.

Because WT L. monocytogenes does not express $\ln t A$ in vitro, we further explored the role played by LntA in the IFN-III signaling pathway using $\ln t A$-constitutive strains. In agreement with the transcriptome data (table S4), ISG expression was higher in LoVo cells infected with $\ln t A \mathrm{v} 5+$ (fig. 3A) or $\ln t A_{\mathrm{c}^{+}}$(fig. S5D) bacteria, compared to non-infected cells or $\ln t A$-infected cells. This effect was observed only in epithelial cell lines (fig. S5E). The expression of CCL5 (fig. 3A) and $I F N-\lambda 2$ (fig. S5F), which are ISGs themselves, was also increased upon infection with $\ln t A$-constitutive strains. Thus, LntA can activate ISGs specifically in Listeria-infected epithelial cells, phenocopying BAHD1 depletion (fig. 2B, S5B). As LntA interacted with BAHD1, we addressed whether it inhibited BAHD1-mediated silencing. Chromatin immunoprecipitation (ChIP) revealed that the recruitment of BAHD1 at the promoter of representative ISGs (IFIT3 and IFITM1) was impaired in lntAv5+-infected cells, compared to lntA--infected cells (fig. 3B). This correlated with an enrichment of acetyl-H3K9 at these genes, consistent with increased transcriptional activity (fig. 3A). Thus, by displacing the BAHD1/HDAC complex from ISGs, LntA de-represses these genes in infected cells (fig. S7).

Neither lntA expression (fig. S3, table S3), nor cellular stimulation with recombinant IFN$\lambda 2$ (fig. S8), altered bacterial infection in tissue-cultured LoVo cells. We thus assessed the consequences of LntA/BAHD1 interactions on the outcome of infection in vivo. To this end, (i) we infected BALB/c mice with $\ln t A$-constitutive or $\ln t A$-deficient bacteria and ( $i i)$ we generated C57BL/6 BAHD1+/- mice (fig. S9, S10) and infected them with WT bacteria. We observed a strong decrease in bacterial burden in spleens and livers of BALB/c mice infected with $\ln t A_{\mathrm{c}^{+}}$or $\ln t A \mathrm{v} 5+$ relative to $\Delta \ln t A$ or WT bacteria, while the IFN- $\lambda 3$ concentration increased in infected organs (fig. 3C and S11). Thus, constitutive expression of $\ln t A$ promotes the IFN-III response and decreases bacterial colonization in vivo. Moreover, in $B A H D 1+$ - mice infected with WT L. monocytogenes, the bacterial burden in organs was reduced compared to $B A H D 1+/+$ mice (fig. 3D). Thus increasing lntA expression in Listeria had similar effects as impairing BAHDl expression in the host, i.e. decreasing infection. Furthermore, while controlled secretion of LntA by WT bacteria is beneficial to the pathogen, either its constitutive 
secretion or its absence is detrimental. We propose that a tight control of $\ln t A$ expression during infection allows Listeria to fine-tune localized immune responses and escape antibacterial response (19). Given the tropism of Listeria (20) and IFN-III (9-13) for epithelia, unraveling the role of LntA in these tissues is now a key issue. Our work identifies the BAHD1 complex as a negative regulator of ISGs in the context of listeriosis, and highlights the importance of chromatin remodeling in bacterial infections.

\section{References}

1. O. Dussurget, Int Rev Cell Mol Biol 270, 1 (2008).

2. $\quad$ P. Cossart, A. Toledo-Arana, Microbes Infect 10, 1041 (Jul, 2008).

3. $\quad$ S. C. Corr, L. A. O'Neill, Cell Microbiol, (Feb 2, 2009).

4. M. A. Hamon, P. Cossart, Cell Host Microbe 4, 100 (Aug 14, 2008).

5. $\quad$ K. Paschos, M. J. Allday, Trends Microbiol 18, 439 (Oct, 2010).

6. A. P. Bhavsar, J. A. Guttman, B. B. Finlay, Nature 449, 827 (Oct 18, 2007).

7. Methods are available as supporting material on Science Online.

8. H. Bierne et al., Proc Natl Acad Sci US A 106, 13826 (Aug 18, 2009).

9. $\quad$ M. Li, X. Liu, Y. Zhou, S. B. Su, J Leukoc Biol 86, 23 (Jul, 2009).

10. R. P. Donnelly, S. V. Kotenko, J Interferon Cytokine Res 30, 555 (Aug, 2010).

11. M. Mordstein, T. Michiels, P. Staeheli, J Interferon Cytokine Res 30, 579 (Aug, 2010).

12. G. Gallagher et al., J Interferon Cytokine Res 30, 603 (Aug, 2010).

13. J. E. Pulverer et al., J Virol 84, 8626 (Sep, 2010).

14. A. Casola et al., $J$ Virol 75, 6428 (Jul 1, 2001).

15. M. Lavigne et al., PLoS Genet 5, e1000769 (Dec, 2009).

16. I. Nusinzon, C. M. Horvath, Proc Natl Acad Sci U S A 100, 14742 (Dec 9, 2003).

17. S. Kamitani et al., Biochem Biophys Res Commun 370, 366 (May 30, 2008).

18. R. Tsuruma et al., Oncogene 27, 3054 (May 8, 2008).

19. Supporting discussion is available on Science Online.

20. M. Lecuit, Clin Microbiol Infect 11, 430 (Jun, 2005).

21. We thank E. Gouin for anti-LntA antibodies; J-Y. Coppee for microarrays facilities at the IP Genopole; S. Jacquot and M.C. Birling at the Targeted Mutagenesis and Transgenesis department of the Mouse Clinical Institute (MCI/ICS), where was generated the $B A H D 1+/$ - mouse line. Work in the Cossart laboratory received financial support from the Pasteur Institute, INRA, INSERM, ANR-ERANET-PathoGenomics (grant SPATELIS), French Ligue Nationale Contre le Cancer (LNCC RS10/75-76 Bierne) and ERC (Advanced Grant 233348). P-J.M. received a PhD fellowship from Région Rhône Alpes. Work in the Cabanes laboratory was supported by FCT (PTDCSAU/MII/65406/2006; PhD fellowship to A.C. SFRH/BD/29314/2006) and ERANETPathoGenomics (grant SPATELIS). P.C. is an international research scholar of the Howard Hughes Medical Institute. 


\section{Figures}
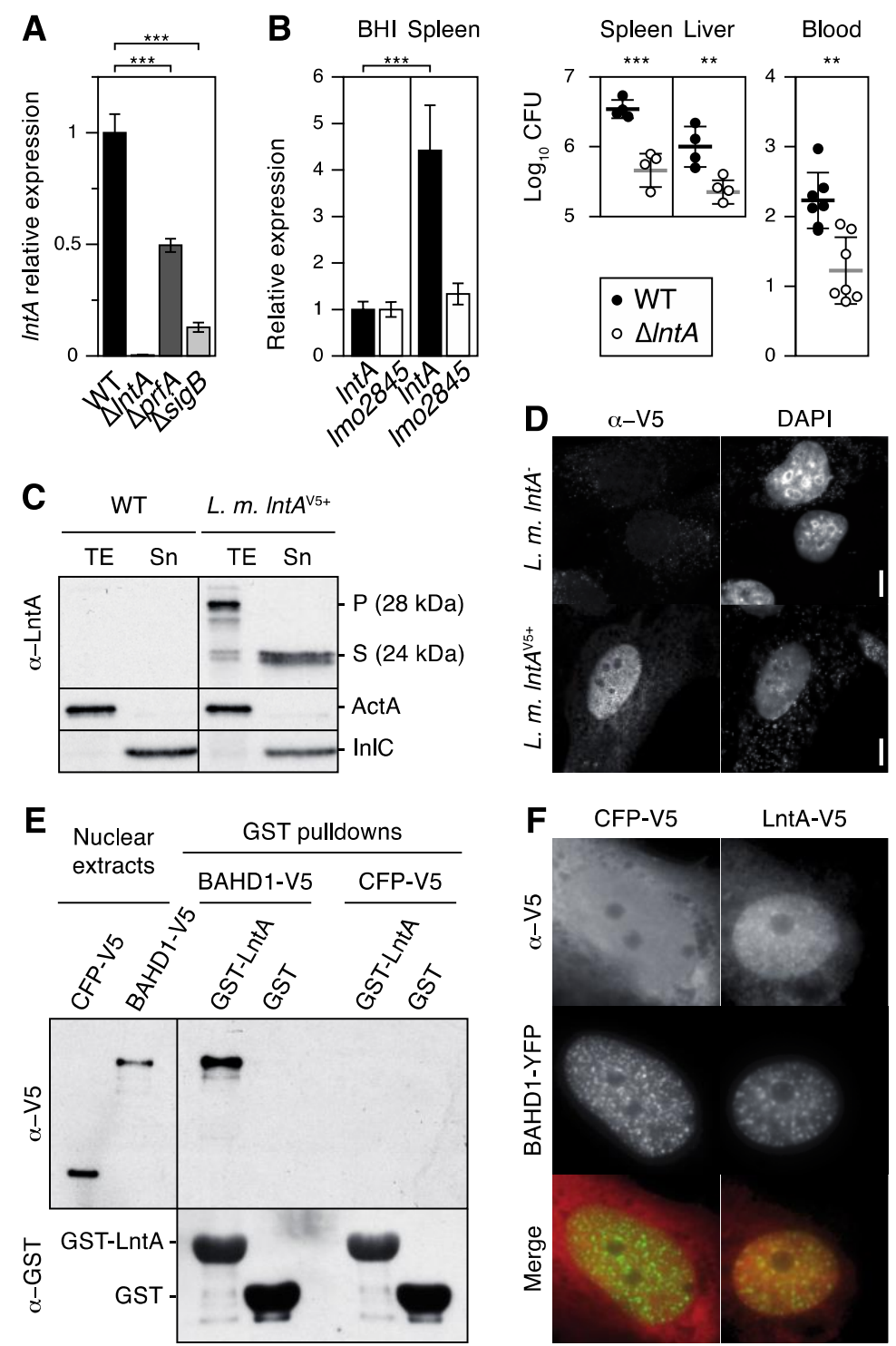

Fig. 1. The secreted virulence factor LntA targets the nuclear protein BAHD1. (A) $\ln t A$ is regulated by PrfA and $\sigma$ B. qRT-PCR analysis of $\operatorname{lnt} A$ levels in WT, $\Delta \ln t A, \Delta p r f A$ or $\Delta \operatorname{sig} B$ strains. (B) $\operatorname{lnt} A$ is up-regulated and contributes to virulence $48 \mathrm{~h}$ post-infection in an intravenous mouse model. Left, qRT-PCR analysis of lntA and control lmo2845 levels in WT Listeria extracted from spleens. Right, bacteria were numerated in organ or $\mathrm{mL}$ blood from mice infected with WT or $\Delta \ln t A$ strains. (A-B) ${ }^{* *}, \mathrm{p}<0.01$; ***, $\mathrm{p}<0.001$ (two-tailed T-tests). (C) LntA is a secreted protein. Bacterial total extracts (TE) and supernatants (Sn) of WT or lntAv5+ strains were analyzed by immunoblot, with ActA and InlC used as controls. WT bacteria do not produce LntA in BHI. P, precursor; S, secreted. (D) LntA localizes to the nucleus of C3SV40 fibroblasts. V5 immunolabelling and DAPI staining in cells infected for $22 \mathrm{~h}$ with lntA- or $\operatorname{lntAv5}$ + bacteria. (E) Purified LntA binds BAHD1. GST or GST-LntA were incubated with nuclear extracts from CFP-V5 or BAHD1-V5 -expressing HEK293 cells. Immunoblots of inputs and eluted fractions were probed with $\alpha-\mathrm{V} 5$ or $\alpha$-GST antibodies. (F) LntA localizes to BAHD1-induced heterochromatin foci. BAHD1-YFP and either LntA-V5 or CFP-V5 were co-transfected into C3SV40 cells and detected by immunofluorescence. (D, F) Bars, $5 \mu \mathrm{m}$. 

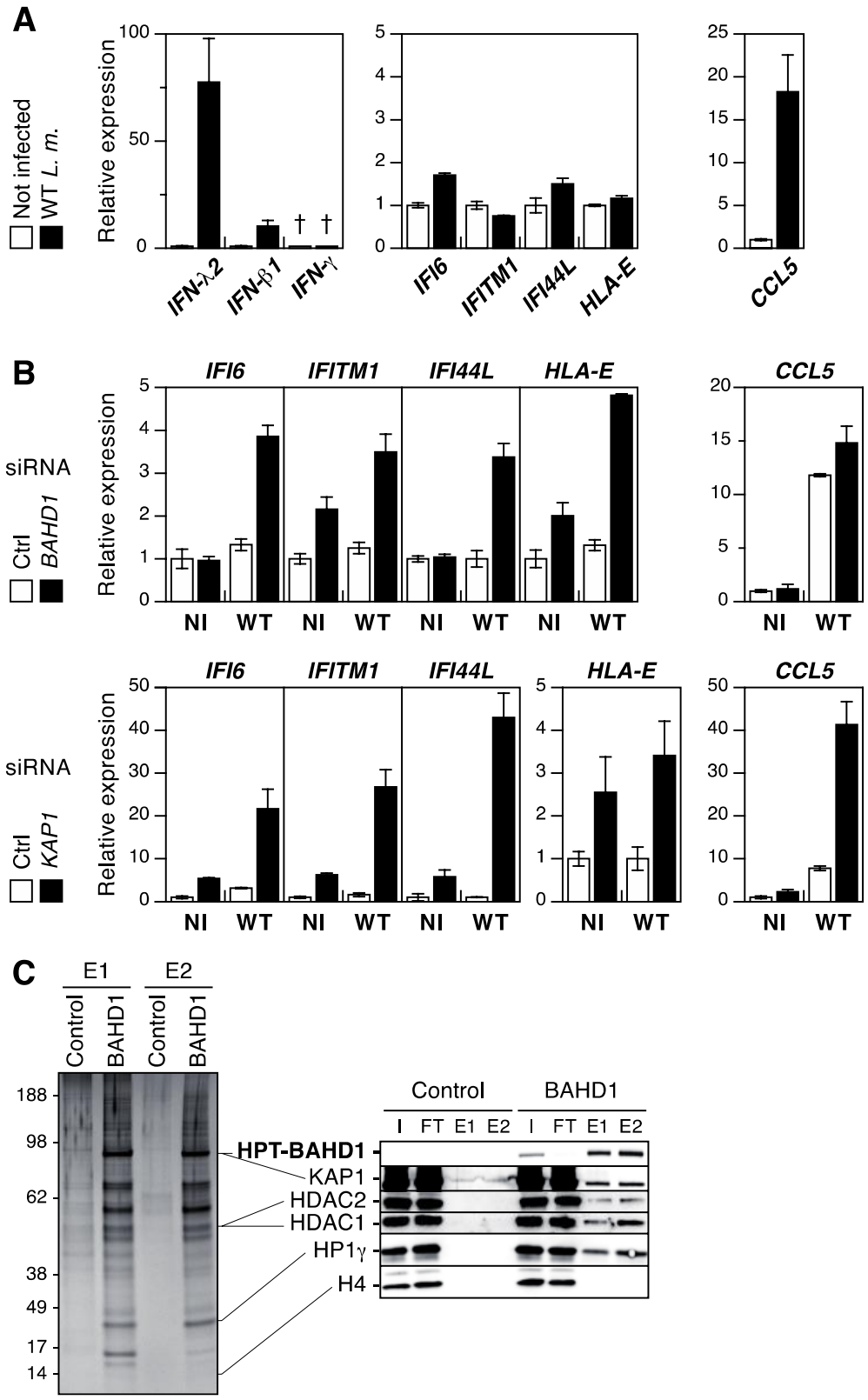

Fig. 2. The BAHD1 complex represses ISGs in Listeria-infected epithelial cells. (A) qRTPCR analysis of IFN and $I S G$ expression in response to Listeria infection in LoVo cells infected for $16 \mathrm{~h}$ with WT L. monocytogenes, compared to non-infected cells. Left: type I (IFN- $\beta 1)$, II $(I F N-\gamma)$ and III (IFN- $\lambda 2)$ interferon genes. Right, various ISGs. †, below detection limits. (B) Quantification of ISGS mRNA in LoVo cells treated for $72 \mathrm{~h}$ with control siRNA, siRNA against BAHDI or KAPl and infected for $16 \mathrm{~h}$ (WT) or not (NI). (C) Tandem-affinity purification of the BAHD1-associated complex. Solubilized chromatin extracts from HEK293 cells expressing the HPT-BAHD1 fusion or control cells were first purified on anti-protein C affinity matrix, followed by polishing on nickel-sepharose. Eluted fractions from the first (E1) and second (E2) affinity columns were analyzed by colloidal coomassie staining (left) or immunoblot (right). I, input; FT, flow through from first column. Histone H4 was a control for non-specific binding of chromatin components. 

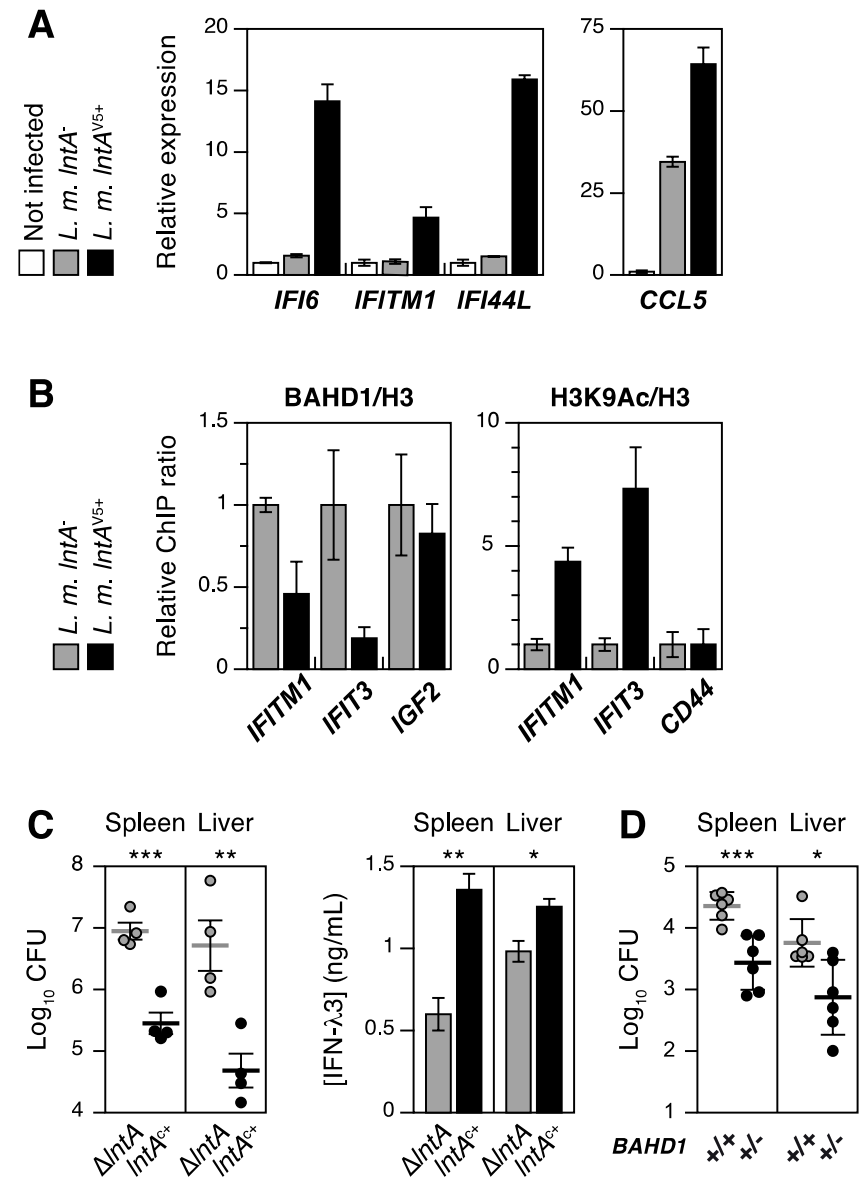

Fig. 3. LntA impairs BAHD1-mediated repression of ISGs. (A) LntA induces ISGs. mRNA levels were estimated by qRT-PCR on total RNA from LoVo cells infected for $16 \mathrm{~h}$ with lntA-

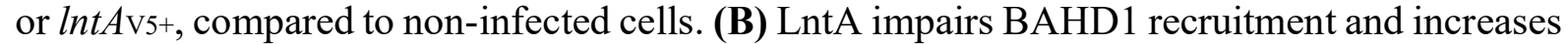
acetyl-H3 levels at ISGs. ChIP analysis was performed on LoVo cells infected as in (A), with antibodies against BAHD1 or H3K9Ac. Promoter DNA levels were assessed by qRT-PCR and normalized to cognate levels in histone H3-ChIP. (C) Constitutive expression of lntA in Listeria decreases bacterial burden during murine systemic listeriosis and triggers overproduction of IFN-III. Mice were infected intravenously with either $\Delta \ln t A$ or $\ln t A_{\mathrm{c}^{+}}$strains. Left, Colony forming units (CFU) per organ were numerated at $72 \mathrm{~h}$ post-infection. Right, Mouse IFN- $\lambda 3$ concentration was quantified by ELISA in clarified total extracts of infected spleens and livers. (D) $B A H D 1+/$ mice are less sensitive to systemic listeriosis. BAHD1+/+ or isogenic BAHD1+/mice were infected intravenously with $L$. monocytogenes EGDe. Colony forming units (CFU) per organ were numerated at $72 \mathrm{~h}$ post-infection. (C-D) ${ }^{*}, \mathrm{p}<0.05 ; * *, \mathrm{p}<0.01 ; * * *, \mathrm{p}<0.001$. 


\title{
Supporting online material
}

\author{
Material and Methods \\ Bacterial strains, culture conditions, plasmids and oligonucleotides \\ Human cell lines \\ Generation of $B A H D 1+/-$ mice \\ Antibodies \\ Yeast two-hybrid (Y2H) screening \\ Transient transfections with plasmids or oligofection with siRNA duplexes \\ Cellular infections, entry and intracellular multiplication assays \\ Animal infections \\ Immunofluorescence analysis, live-cell imaging and image processing \\ Bacterial extracts, SDS-PAGE and immunoblots \\ GST-pulldowns \\ Expression and purification of LntA for cristallography \\ Crystallization, structure solution and refinement \\ Tandem affinity purification of the HPT-BAHD1-associated complex and mass spectrometry analysis \\ NanoLC-MS/MS analyses for protein identification \\ Sandwich ELISA measurement of mouse IFN- $\lambda 3$ in organ homogenates \\ Bacterial RNA extraction and qRT-PCR \\ Transcriptome analysis of infected cells \\ Human and mice RNA extraction and qRT-PCR \\ Chromatin immunoprecipitation experiments and site-specific PCR analysis

\section{SOM text} \\ Roles of type I, II and III interferons in listeriosis \\ Influence of the genetic background on the outcome of murine listeriosis
}

\section{Supporting Figures}

Fig. S1. Identification of $\ln t A$ as a candidate virulence gene encoding a secreted protein.

Fig. S2. LntA folds into a compact helical structure.

Fig. S3. Deletion or constitutive expression of $\ln t A$ does not alter bacterial invasion of host cells.

Fig. S4. LntA colocalizes with BAHD1 in the nucleus of human living cells.

Fig. S5. Expression of interferon genes and ISGs in response to Listeria infection.

Fig. S6. Tandem-affinity purification of the HPT-BAHD1 associated complex.

Fig. S7. Proposed model for BAHD1/LntA-mediated regulation of ISGs.

Fig. S8. Bacterial intracellular multiplication in LoVo cells is not altered by IFN- $\lambda$-stimulation.

Fig. S9. Verification of the $B A H D 1 \mathrm{KO}$ allele.

Fig. S10. Genotyping of $B A H D 1+$ - mice.

Fig. S11. Both deletion and constitutive expression of $\operatorname{lnt} A$ in Listeria decrease bacterial burden during murine systemic listeriosis.

\section{Supporting Tables}

Table S1. Bacterial strains.

Table S2. Plasmids.

Table S3. Bacterial entry in LoVo cells is independent of $\operatorname{lnt} A$ expression and is not altered by IFN- $\lambda 2$ treatment.

Table S4. Transcriptome data - genes activated by LntA in infected LoVo cells.

Table S5. Oligonucleotides.

Table S6. PCR products and digests for the validation of $B A H D 1+/$ - mice.

Table S7. Crystallography. Data collection, phasing and refinement statistics.

\section{References}




\section{Material and Methods}

\section{Bacterial strains, culture conditions, plasmids and oligonucleotides}

Strains, plasmids and oligonucleotides used in this work are recapitulated in tables S1, S2, and S5, respectively. Listeria and Escherichia coli strains were grown in brain-heart infusion (BHI) or Luria-Bertani (LB) media (Difco), respectively, at $37^{\circ} \mathrm{C}$. When appropriate, antibiotics were included in media at the following concentrations: kanamycin, $30 \mu \mathrm{g} / \mathrm{ml}$; ampicillin, $100 \mu \mathrm{g} / \mathrm{ml}$, colistin, $10 \mu \mathrm{g} / \mathrm{ml}$; nalidixic acid, $50 \mu \mathrm{g} / \mathrm{ml}$; erythromycine, $5 \mu \mathrm{g} / \mathrm{ml}$; chloramphenicol, $7 \mu \mathrm{g} / \mathrm{ml}$ for Listeria, $35 \mu \mathrm{g} / \mathrm{ml}$ for E. coli.

For heterologous expression constructs of C-terminally tagged LntA fusions, the $\operatorname{lntA}$ (lmo0438, Gen-bank/EMBL accession number AL591975, 1) Open Reading Frame (ORF) without the sequence encoding the signal peptide (residues Gly34 to Lys205) was introduced into pcDNA3.1/V5-His-TOPO using the directional topoisomerase cloning system (Invitrogen). Fluorescence microscopy, two-hybrid and GST-fusion protein expression constructs were generated by sub-cloning lntA into pE-mCFP-N1 (2), pB27 (Hybrigenics) pET41a (Novagen), and pGEX-4T-1 (GE Healthcare) respectively.

To constitutively express $\ln t A$ in Listeria, we inserted the complete $\ln t A$ ORF, fused with a V5 tag, into the pP1 multicopy plasmid, downstream of the constitutive PPRT promoter of the protease gene from Streptococcus cremoris (3). This plasmid expressing $\ln t A-\mathrm{V} 5$ was electroporated into L. monocytogenes EGDe, generating BUG2384 (referred to as $\operatorname{lntAv5+}$ ). As a control, the empty $\mathrm{pP} 1$ vector was electroporated into EGDe $\triangle \ln t A$, generating BUG2466 (referred to as $\ln t \mathrm{~A}_{-}^{-}$).

We additionally designed a Listeria strain where a non-tagged copy of $\ln t A$ was integrated in the Listeria genome at the $T R N A A R G$ locus using the pPL2 shuttle system (4). A pPL2 vector carrying a PHYPER-5'-UTRhly-lntA transcriptional fusion was transformed into the EGDe $\Delta \ln t A$ strain by conjugation, yielding to the complemented strain BUG2822 (referred to as $\operatorname{lnt} A A_{\mathrm{c}+}$ ). A isogenic $\Delta \operatorname{lnt} A$ :pPL2 control strain was also generated with the empty pPL2 vector (BUG2820, referred to as $\left.l n t A_{\mathrm{c}-}\right)$. Selected integrants were confirmed by PCR.

To engineer a stable cell line producing the HPT-BAHD1 fusion, and a control cell line, we designed the following plasmids. First, the Tet operator sequence (TO) was introduced into pcDNA5/FRT-HPT-blue (a derivative of pCDNA5/FRT/V5-His from Invitrogen, 5). This gave rise to pcDNA5/FRT/TO-HPT-blue, allowing the N-terminal fusion of any inserted sequence with the HPT tag, e.g. a 6xHis tag, followed by the Protein $\mathrm{C}$ epitope and by a TEV cleavage site: MHHHHHH-EDQVDPRLIDGK-gggdydiptt-ENLYFQG-amgrp. Due to the Tet operator, the expression of the fusion is repressed by the Tet repressor in Flp-In T-Rex 293 cells (Invitrogen), but can be activated by addition of tetracycline to the culture medium. BAHD1 was cloned in pcDNA5/FRT/TO-HPT-blue to give rise to pcDNA5/FRT/TO-HPT-BAHD1, expressing HPT-tagged $B A H D 1$ in a tetracycline-dependent manner. In the control pcDNA5/FRT/TO-HPT-blue plasmid, the tag is fused to a single T codon before the stop codon.

All constructs were verified by double-strand sequencing. Additional cloning details are available upon request.

\section{Human cell lines}

We used C3SV40 fibroblasts (6), intestinal epithelial LoVo cells (ATCC CCL-229), placental JEG-3 cells (ATCC HTB-36), U-937 and THP-1 monocytes (CRL-1593.2 and TIB202 respectively), HEK293 embryonic kidney cells (CRL-1573), and HEK293-derived Flp-In T-Rex 293 cells (Invitrogen). C3SV40 cells were grown in RPMI 1640 (Gibco) supplemented with 10\% FCS (Gibco); other cell lines were grown following ATCC or Invitrogen 
recommendations. All cells were cultured at $37^{\circ} \mathrm{C}$ in a humidified atmosphere containing $10 \%$ $\mathrm{CO}_{2}$.

Stable HEK293-HPT-BAHD1 and control HEK293-HPT-blue cells were generated as follows. Flp-In T-Rex 293 were transfected with the pcDNA5/FRT/TO-HPT-BAHD1 or -blue plasmids, together with the plasmid encoding the Flp recombinase. Stable pool of transfectants having undergone integration of HPT-expressing plasmids at the single FRT locus were selected as described (7), with the exception that $15 \mu \mathrm{g} / \mathrm{ml}$ of Blasticidin (Invivogen) was added to the culture media in order to select for the maintenance of Tet repressor expression.

For BAHD1 complex purification, HEK293-HPT-BAHD1 and control -blue cells were grown in 3-L spinners in DMEM, 10\% fetal calf serum, 1\% Penicillin/Streptomycin under 5\% $\mathrm{CO}_{2}$ atmosphere. To induce the production of the HPT-BAHD1 fusion, tetracycline was added to cell culture media $24 \mathrm{~h}$ before cell recovery at a final concentration of $11 \mu \mathrm{g} / \mathrm{ml}$. Cell pellets were recovered by centrifugation, PBS-washed, flash-frozen in liquid nitrogen and stored at $80^{\circ} \mathrm{C}$ until they were use for tandem affinity purification.

\section{Generation of $B A H D 1+/-$ mice}

The BAHD1 mutant mouse line was established at the MCI/ICS (Mouse Clinical Institute, Institut Clinique de la Souris, Illkirch, France; http://www-mci.u-strasbg.fr). The entire coding region of the BAHD1 allele (Ensembl Gene ID: ENSMUSG00000040007) including the intronic sequences was replaced with a floxed neomycin cassette. The targeting vector was constructed as follows. A 4.3-kb fragment upstream of BAHD1 exon 2 and a $4.3 \mathrm{~kb}$ fragment downstream of BAHD1 exon 7 were PCR-amplified and subcloned upstream and downstream of a floxed Neomycin (Neo) resistance cassette into an MCI proprietary vector, which contains the thymidine kinase gene for a negative selection. The linearized construct was electroporated in C57BL/6 mouse embryonic stem (ES) cells. After selection, targeted clones were identified by PCR amplification using external primers (Ef1/Nr1), and were further confirmed by Southern blot with an internal Neo probe and an external probe (table S6 and fig. S9). Five clones amongst 372 clones were positive. Two positive ES clones were injected into BALB/c recipient blastocysts and the derived male chimaeras showed efficient germline transmission. $\mathrm{C} 57 \mathrm{BL} / 6$ mice derived from clone \#41 were used for this study. Excision of the Neo resistance cassette was done at the chimera level, by breeding chimeras directly with C57BL/6 Cre deleter mouse line. F1 C57BL/6 Cre progeny were genotyped from mouse-tail lysates, using Ef and Er primers (outside of targeted exons), $\mathrm{Wr}$ and $\mathrm{Wf}$ (inside targeted exons), $\mathrm{Nr}$ and $\mathrm{Nf}$ (inside the Neo cassette) and Lxr (probing the loxP site). Details about primers and genotyping results are given in tables S5, S6 and fig. S10A. Analysis of PCR product patterns was performed by using HT DNA $5 \mathrm{~K}$ LabChip ${ }_{\otimes} 90$ kit on the LabChip ${ }_{\otimes} 90$ microfluidic electrophoresis apparatus. A representative genotyping picture is shown in fig. S10B.

\section{Antibodies}

The primary antibodies were as follows: anti-InlC (R134, 8); anti-ActA (R32, 9) and antiLLO (R176, 10) rabbit polyclonal antibodies; anti-V5, anti-V5-HRP and anti-V5-FITC mouse monoclonal antibodies (R960-25, R961-25 and R963-25, Invitrogen); anti-GST mouse monoclonal antibody (71097, Novagen); anti-HP1 $\gamma$ mouse monoclonal antibody (2MOD-1G6AS, Euromedex); anti-BAHD1, H3, H4, KAP1, HDAC1 and HDAC2 rabbit polyclonal antibodies (ab46573, ab1711, ab7311, ab10483, ab7028 and ab7029 respectively, Abcam); anti-protein C mouse monoclonal antibody, clone HPC4 (11814508001, Roche); anti-H3K9Ac rabbit polyclonal antibody (9671, Cell Signaling Technology). The anti-LntA rabbit polyclonal antibody was generated and purified against recombinant GST-LntA as described (11). It was used at a 1:1,000 dilution in immunoblots. Secondary antibodies were Cy3-conjugated goat 
anti-mouse IgGs (115-167-003, Jackson IR) for immunofluorescence (1:500 dilution), and HRP-conjugated goat anti-mouse or anti-rabbit IgGs (172-1011 or 172-1019, Bio-Rad) for immunoblots (1:10,000 dilution).

\section{Yeast two-hybrid (Y2H) screening}

The bait construct was the $\ln t A$ gene cloned in $\mathrm{pB} 27$, a $\mathrm{Y} 2 \mathrm{H}$ vector optimized by Hybrigenics, S.A., Paris, France (http://www.hybrigenics.com). pB27-lntA was transformed in the L40DGAL4 yeast strain (12) and $\mathrm{Y} 2 \mathrm{H}$ screening was performed by Hybrigenics, as described (6). 107.42 millions of interactions were actually tested with the LntA bait. After selection on medium lacking leucine, tryptophane, and histidine, positive clones were picked and the corresponding prey fragments were amplified by PCR and sequenced at their 5' and 3' junctions. Sequences were then filtered and contiged as described previously (13) and compared to the latest release of the GenBank database using BLAST (14). In the LntA screening process, BAHD1 was found in 9 independent clones, with a Predicted Biological Score of A (very high confidence), as for two other preys.

\section{Transient transfections with plasmids or oligofection with siRNA duplexes}

Transient transfections of plasmids were performed as previously described (15) using lipofectamine 2000 (Invitrogen), according the manufacturer's protocol. Chemically synthesized siRNAs against BAHD1 (S22351 and S22352 Silencer ${ }^{8}$ siRNA) or KAP1 (siGENOME SMARTpool M-005046-01) were purchased from Ambion or Dharmacon, respectively. The corresponding Silencer ${ }^{\circledR}$ Negative Control \#1 siRNA (AM4611) and siGENOME Non-Targeting siRNA pool (D-001206-14) were used as controls. LoVo cells were transfected using Lipofectamine RNAiMAX (Invitrogen) following the manufacturer's instructions. Briefly, 106 LoVo cells per well of a 6-well plate were first treated with a reversetransfection protocol, using $5 \mu \mathrm{l}$ lipofectamine RNAiMAX and 50 pmol of siRNA. This was followed by a forward transfection $30 \mathrm{~h}$ later, using the same amounts of siRNA and transfection agent. The silencing efficiency of these siRNAs for their targeted mRNA was tested by qRT-PCR as described below, $72 \mathrm{~h}$ post-transfection. Displayed BAHD1 silencing results proceed from S22351 transfection; S22352 gave comparable phenotypes, though with a weaker efficiency.

\section{Cellular infections, entry and intracellular multiplication assays}

In all invasion experiments, Listeria strains were grown in BHI medium to an $\mathrm{OD}_{600}$ of 2 to 3 , washed in PBS, and diluted in culture medium without serum, to achieve the required the multiplicity of infection (MOI). Bacterial dilutions were added to cell plates and centrifuged for 1 minute at $200 \mathrm{x}$ g to synchronize entry (except for chromatin immunoprecipitations, for which $162 \mathrm{~cm} 2$ cell flasks were used). After $1 \mathrm{~h}$ of incubation, cells were washed twice and the remaining non-invasive bacteria were killed by adding gentamicin $20 \mu \mathrm{g} / \mathrm{ml}$ in complete culture medium for $1 \mathrm{~h}$ (entry) to $15 \mathrm{~h}, 21 \mathrm{~h}$ or $23 \mathrm{~h}$ (intracellular multiplication).

Specific protocols were as follows:

(i) Quantifications of bacterial entry and intracellular multiplication by gentamicin survival assays (16). Bacterial dilutions were added to LoVo cells seeded in 24-well plates, to obtain a MOI of 20 to 40. After entry and gentamicin treatment, efficiencies of bacterial entry and intracellular multiplication were quantified by plating serial dilutions of cells lysates on BHI agar plates and determining colony-forming units (CFU). Experiments were performed in triplicates and reproduced at least three times. When applicable (fig. S8, table S3B), recombinant human IL-28A/IFN- $\lambda 2$ (R\&D system, 1587-IL-025) was added either $24 \mathrm{~h}$ before or concomitantly with gentamicin at the indicated concentrations. 
(ii) Microscopy. C3SV40 cells were seeded on glass coverslips in six-well plates and infected or not with bacteria at a MOI of 100 . After $22 \mathrm{~h}$ of infection, coverslips were processed for immunofluorescence analysis. As bacterial entry is mainly InlB-dependent in C3SV40 cells, for quantification experiments, we increased the number of infected cells by treating bacteria with the invasion protein InlB-Ami, which is able to efficiently associate to the bacterial surface when added exogenously, and to stimulate bacterial entry (17). After 30 minutes of incubation at $37^{\circ} \mathrm{C}$, bacteria were washed twice in PBS and used for cell infection, as described above.

(iii) RNA analysis. Cells were seeded in six-well plates and infected or not with bacteria at a multiplicity of infection (MOI) of 20, and processed as for invasion assays. RNA samples were collected 16 to $24 \mathrm{~h}$ post infection. When siRNA treatment was needed, this was performed as described above, starting the reverse-transfection protocol 72 hours before recovery of infected cells (i.e. $56 \mathrm{~h}$ before infection for the reverse transfection, and $26 \mathrm{~h}$ for the forward transfection). Note that, for optimal siRNA treatment, cells had to be seeded at a lower density in these experiments than non-siRNA treated cells. This resulted in decreased cell-to-cell spread of bacteria. As a consequence, the observed effects of infection on the expression of IFN genes and ISGs were less pronounced for siRNA treated cells, in control as well as in targeted depletion samples. U-937 and THP-1 monocytes were pre-activated by adding $1 \mathrm{mg} / \mathrm{ml}$ PMA (phorbol-12-myristate-13-acetate, Sigma) to the culture medium, 24 hours before infection.

(iv) Chromatin ImmunoPrecipitations (ChIP). LoVo cell monolayers in $162 \mathrm{~cm} 2$ flasks were infected with $\ln t A$ - or $\ln t A \mathrm{v} 5+$ strains at a multiplicity of infection (MOI) of 25 . After $16 \mathrm{~h}$ of infection, cells were washed in PBS and fixed with 1\% formaldehyde in PBS as described (18). For microscopy, RNA and ChIP experiments, we controlled the efficiency of infection by CFU counts on lysed cells, and by immunofluorescence using anti-Listeria antibody. Bacterial recovery of the $\ln t A$-expressing or -deficient strains proved to be very similar in every condition tested, thus excluding potential effects of bacterial load/entry/survival/proliferation variations on the described phenotypes.

\section{Animal infections}

Animal experiments were performed according to the Institut Pasteur guidelines for laboratory animal husbandry, which comply with European regulations.

(i) In vivo virulence assay in $\mathrm{BALB} / \mathrm{c}$ mice. 8-week-old female $\mathrm{BALB} / \mathrm{c}$ mice (Charles River) were injected intravenously with $L$. monocytogenes strains to be tested. Groups of 4 (for organs) to 6 (for blood) mice were injected with an inoculum of 8.103 CFU per tested strain, and sacrificed 48 or $72 \mathrm{~h}$ after infection. Spleens and livers were aseptically removed and separately disrupted in phosphate-buffered saline (PBS). $100 \mu \mathrm{l}$ of blood was recovered and heparin (250 units $/ \mathrm{ml}$ ) was added to prevent coagulation. Serial dilutions of organs homogenates or blood were plated on BHI agar plates and CFU determined. Statistical analyses were performed using Student's two-tailed T-test on CFU counts. A p-value $\mathrm{p}<0.05\left(^{*}\right)$ was considered statistically significant.

Note that, when we assayed the virulence of the $\Delta \operatorname{lnt} A$ mutant strains, comparable results were obtained with clone BUG2168 (fig. 1B and 3C) and with BUG2169 (not shown).

(ii) In vivo virulence assay in $B A H D 1+/+$ or $B A H D 1+/$ - mice. Six mice carrying the $B A H D 1 \mathrm{KO}$ (knockout) allele on one chromosome $(B A H D 1+/-)$ and six of their littermates carrying the wild type (WT) allele $(B A H D 1+++)$ were used in this study. Each group contained 5 males and 1 female, all in the C57BL/6 background. These mice were injected intraperitoneally with WT EGDe. Due to resistance of C57BL/6 mice to infection by L. monocytogenes (19), we used an inoculum of 5. $104 \mathrm{CFU}$ per animal. Mice were sacrificed $72 \mathrm{~h}$ after infection, and CFU were numerated in organs as described in $(i)$. 
(iii) In vivo RNA analysis. Bacteria were isolated from mouse spleens as previously described (20). Briefly, 6-8 weeks old specific pathogen-free female CD1 mice (Charles River) were intravenously infected with $106 \mathrm{~L}$. monocytogenes EGDe bacteria. $48 \mathrm{~h}$ post-infection, spleens were harvested and homogenized in ice-cold solution $(0.2 \mathrm{M}$ sucrose, $0.01 \% \mathrm{SDS})$. The homogenate was gently centrifuged for 20 minutes at $300 \mathrm{rpm}$ and filtered. The tissue suspension was centrifuged for 20 minutes at $4000 \mathrm{rpm}$ to pellet the bacteria.

\section{Immunofluorescence analysis, live-cell imaging and image processing}

(i) For microscopy on fixed samples, cells were fixed 20 minutes at room temperature with 4\% paraformaldehyde in PBS, permeabilized with $0.5 \%$ Triton X-100 in PBS for 4 minutes at room temperature, and then blocked in PBS containing 1\% BSA (Sigma). Slides were then incubated either with FITC-conjugated anti-V5 for 1 hour or, when co-localizations of LntA-V5 with BAHD1-YFP was needed, with primary anti-V5 for 1 hour and then with Cy3-conjugated secondary antibody and DAPI for 30 minutes. Bacteria were visualized in phase contrast and with DAPI.

(ii) For live cell imaging, images were acquired with the microscope equipped with a temperature-controled stage and an objective heater (Biotechs). Fluorescent illumination was driven by an ultrahigh-speed wavelength switcher Lamda DG4 (Sutter Instrument) equipped with a 175W xenon arc lamp and excitation filters for CFP and YFP (Chroma Technology). Emission filters were selected using a high-speed Lamda 10 filter wheel (Sutter Instrument).

Preparations were observed with a Zeiss Axiovert 200M epifluorescence microscope (Carl Zeiss MicroImaging, Inc.), connected to a cooled CCD camera (CoolSNAPне, Photometrics). Images were acquired with apochromat $63 \mathrm{x}$ or 100x (NA 1.4) objective lenses and processed with the MetaMorph software, version 6.1 (Universal Imaging Corp., Downingtown, PA).

To quantify LntA signals in nuclei of C3SV40 cells infected with $\ln t A-V 5+$, a region encompassing the surface of each nucleus, corresponding to the DAPI staining, was created in MetaMorph. FITC Fluorescence intensity (average intensity, expressed in arbitrary units, a.u.) was then measured in the selected area, in the image corresponding to the LntA-V5 staining. V5-specific FITC staining was compared with the background FITC staining in C3SV40 cells, or cells infected with the control strain $\ln t A_{-}$. Data were gathered from 26 nuclei in three independent experiments, and background levels, collected from cell-free areas of the coverslip, were subtracted. Acquisition parameters and background levels were similar same for all samples.

\section{Bacterial extracts, SDS-PAGE and immunoblots}

Bacterial total extracts or culture supernatants were recovered from $1 \mathrm{ml}$ of Listeria strains grown to a $\mathrm{OD} 600$ of 2.0 in $\mathrm{BH} 1$ medium at $37^{\circ} \mathrm{C}$, under microareroby conditions. After centrifugation at $8,000 \mathrm{xg}$, the bacterial pellet was resuspended in $100 \mu \mathrm{l} 2 \mathrm{x}$ concentrated protein electrophoresis sample buffer (SB2X, 21), sonicated 5 times 15 seconds, and boiled for 5 minutes at $95^{\circ} \mathrm{C}$. Supernatants were filtered on $0.2 \mu \mathrm{m}$ filters, precipitated with $16 \%$ TCA for 30 minutes at $4{ }^{\circ} \mathrm{C}$ and by centrifugated for 15 minutes at $4^{\circ} \mathrm{C}$. The precipitated proteins were washed with acetone, and denaturated in $100 \mu \mathrm{l} \mathrm{SB} 2 \mathrm{X}$. $10 \mu \mathrm{l}$ of each sample were separated by electrophoresis on $14 \%$ sodium dodecyl sulfate-polyacrylamide gels (SDS-PAGE). Proteins were detected by immunoblot using Hybond-P PVDF membranes (GE Healthcare) and a detection kit (Pierce).

\section{GST-pulldowns}

To prepare nuclear extracts, 4.107 HEK293 cells transfected or not with pcDNA3.1/V5-HisTOPO- $m C F P$, or pcDNA3.1/V5-His-TOPO-BAHD1 were harvested and proceeded with a 
Nuclear Extraction Kit (Active Motif), following manufacturer's instructions. Nuclear and cytoplasmic extracts were stored at $-80^{\circ} \mathrm{C}$. GST-LntA or GST were produced from BL21(DE3) transformed with pET41a plasmids. $300 \mathrm{ml}$ of cultures at DO600 $=0.6$ were stimulated $4 \mathrm{~h}$ with $0.5 \mathrm{mM}$ IPTG. Bacterial pellets were lysed with a French Press (13,000 PSI) in lysis buffer (15 mM HEPES pH 8.0, $100 \mathrm{mM} \mathrm{NaCl}, 1$ mM EDTA, $1 \mathrm{mM}$ DTT) supplemented with Complete protease inhibitor cocktail, EDTA-free (Roche). For pull down assays, $100 \mu \mathrm{l}$ of a $50 \%$ slurry of gluthatione sepharose 4B beads (Amersham, Biosciences) were mixed for $4 \mathrm{~h}$ at $4{ }^{\circ} \mathrm{C}$ with bacterial lysates and processed according to the manufacturer's instructions. The amount of GST fusion proteins was estimated by either immunoblot or Coomassie brilliant blue staining for normalization of quantities used in pulldown assay. $50 \mu \mathrm{l}$ of purified nuclear extract containing BAHD1-V5 or CFP-V5 were mixed with appropriated quantities of GST fusion protein resin in supplemented binding buffer and incubated overnight at $4^{\circ} \mathrm{C}$. The beads were then washed twice with the same binding buffer and once with binding buffer without protease inhibitor cocktail. $20 \mu \mathrm{l}$ of SB2X was added and the mixture was denaturated for 6 minutes at $100^{\circ} \mathrm{C}$. After centrifugation at 2,500 x g for $5 \mathrm{mn}, 15 \mu \mathrm{l}$ of the supernatant was subjected to SDS-PAGE and immunoblot as described above.

\section{Expression and purification of LntA for cristallography}

E. coli BL21(DE3) were transformed with pGEX-lntA plasmid. Cultures were grown at $37^{\circ} \mathrm{C}$ to $\mathrm{OD}_{600}=0.8$, then expression was induced by addition of $1 \mathrm{mM}$ IPTG for 21 hours at $25^{\circ} \mathrm{C}$. Cells were disrupted by sonication in PBS buffer $\mathrm{pH} 7.3$ supplemented with $140 \mathrm{mM}$ $\mathrm{NaCl}$, protease inhibitors, DNaseI (Sigma) and RNAse (Roche). The sample was centrifuged at $30,000 \mathrm{xg}$ for $1 \mathrm{~h} 30 \mathrm{~min}$, and the supernatant was loaded onto a $5 \mathrm{ml}$ GSTrap-HP column (GE Healthcare) equilibrated in PBS buffer. The GST-LntA34-205 fusion protein was eluted with $20 \mathrm{mM}$ reduced glutathione in $50 \mathrm{mM}$ Tris- $\mathrm{HCl}, \mathrm{pH}$ 8.0. After dialysis into a buffer containing $25 \mathrm{mM}$ Tris-HCl pH 8.3 and $0.2 \mathrm{M} \mathrm{NaCl}$, the GST-tag was cleaved for 6 hours with $0.5 \mathrm{U}$ of thrombin/mg of protein. The digested sample was reloaded onto the GSTrap-HP column and the unbound fraction was loaded onto a Superdex 75 column equilibrated in 25 mM HEPES, $0.1 \mathrm{M} \mathrm{NaCl}, 1 \mathrm{mM}$ EDTA, $\mathrm{pH}$ 7.5. The selenomethionine form of LntA was expressed in minimal medium and purified as for the native protein, except that $5 \mathrm{mM}$ DTT was added to the GST equilibration buffer and an additional MonoQ HR5/5 step was performed at $\mathrm{pH} 8.0$ before gel filtration. Mass spectrometry confirmed the full substitution of the three methionines.

\section{Crystallization, structure solution and refinement}

Purified LntA34-205 was concentrated to $10 \mathrm{mg} / \mathrm{ml}$, and an initial screening using the high throughput crystallization platform of the HTXLab (PSB, Grenoble, France) performed at $4^{\circ} \mathrm{C}$ yielded more than 100 different hits. Several crystal forms were reproduced by hand at $20^{\circ} \mathrm{C}$. The best crystals grew in 2 months in $0.15 \mathrm{M} \mathrm{NaSO}$, 18\% PEG 3350 and, before data collection, were cryoprotected by successive incubation in mother liquor containing increasing concentrations of glycerol (up to $25 \%$ ).

A SAD-dataset on the Selenium edge was collected on BM30A at the ESRF-Grenoble to a resolution up to $2.3 \AA$. Data were indexed (space group P41212) and scaled with the XDS package (22). Heavy atoms sites, refinement and phasing were performed by AutoSHARP (23, 24). Cycles of intercalated automatic and manual building were performed using ARP/wARP and Coot $(25,26)$, coupled with refinement cycles by REFMAC 5.4 (27). Data collection and refinement statistics are shown in table S7.

The LntA molecular structure data are deposited at the Worldwide Protein Data Bank (http://www.wwpdb.org/), ID \#2x14, structure factor file \#r2x14sf. 


\section{Tandem affinity purification of the HPT-BAHD1-associated complex and mass spectrometry analysis}

We carried out a double-affinity purification of HPT-BAHD1 from HEK293-HPT-BAHD1 cells, or a negative control purification from HEK293-HPT-blue cells, starting from $7.5 \mathrm{~g}$ of frozen cellular pellet. Preparation of nuclear soluble and chromatin fractions was as described (28). HPT-tagged BAHD1 associated complexes were then purified by two-step affinity chromatography using ( $i$ ) Anti-Protein C Affinity Matrix (Roche) for the binding of the protein C epitope and (ii) Ni Sepharose High Performance (GE Healthcare) for the binding of the His6tag. Since the recognition of the protein $\mathrm{C}$ epitope by the HPC4 antibody is calcium-sensitive, no EDTA was added in the first chromatography step. Instead, TGN binding and wash buffer (20 mM Tris pH 7.65, 10\% glycerol, $150 \mathrm{mM} \mathrm{NaCl}, 0,01 \%$ Igepal) was supplemented with $1 \mathrm{mM} \mathrm{CaCl}$. After overnight binding to the resin, bound complexes were extensively washed, and then eluted with TEGN (TGN, 5 mM EGTA, pH 7.65). Eluates were supplemented with $30 \mathrm{mM}$ imidazole and further affinity-purified on Ni-sepharose. After $2 \mathrm{~h}$ of binding to the resin, bound complexes were extensively washed with TIGN (TGN, $30 \mathrm{mM}$ imidazole, $\mathrm{pH}$ 7.65), and eluted with $2 \mathrm{X}$ NuPAGE LDS sample buffer (Invitrogen). Doubleimmunopurified complexes were resolved on NuPAGE Novex 4-12\% Bis-Tris gels in MOPS buffer (Invitrogen). For the analytical gels (fig. 2C and S6A), we loaded 1/100th of the eluate from the 1 st column, and1/10th of the eluate from the 2 nd column, and stained with the SilverQuest staining kit (Invitrogen). For control immunoblots, we loaded 1/1,000th and 1/100th of the two eluates, respectively, and 1/10,000th of the input and flow through fractions. For the preparative gel (fig. S6B), we loaded $1 / 4$ th of the eluates from the 1 st and 2 nd columns, and stained with Colloidal Blue staining kit (Invitrogen). Bands were cut out from the two-spep purified complex lane for mass spectrometry (MS) analyses (see below).

\section{NanoLC-MS/MS analyses for protein identification}

Standard enzymatic digestion of excised bands was performed with trypsin (Gold Promega $10 \mathrm{ng} / \mu \mathrm{l}$ ) using the Progest robot (Genomic Solutions). Peptide mixtures were SpeedVac-treated for 10 min then solubilized with $0.1 \%$ formic acid and injected in a Q-TOF Premier mass spectrometer coupled to a nanoAcquity liquid chromatography equipped with a trapping column (Symmetry $\mathrm{C} 18,180 \mu \mathrm{m} \times 20 \mathrm{~mm}, 5 \mu \mathrm{m}$ particle size) and an analytical column (BEH130 C18, $75 \mu \mathrm{m} \times 100 \mathrm{~mm}, 1.7 \mu \mathrm{m}$ particle size) (Waters). The aqueous solvent (buffer A) was $0.1 \%$ formic acid in water and the organic phase (buffer B) was $0.1 \%$ formic acid in acetonitrile. A 2-40\% B gradient was set for 25 min. For exact mass measurements, glufibrinopeptide reference $(\mathrm{m} / \mathrm{z}=785.8426)$ was continuously supplied during nanoLCMS/MS analyses using the lockspray device. Peptide mass measurements were corrected during data processing and peak lists were generated by PLGS (ProteinLynx Global Server, Waters). Processed data were submitted to Mascot searching using the following parameters: data bank NCBI; taxonomy Human; peptide tolerance $20 \mathrm{ppm}$; fragment tolerance $0.1 \mathrm{Da}$; digest reagent trypsin with one missed cleavage allowed; variable modifications oxidation (Methionine) and fixed modifications carbamidomethylation (Cysteine). Validation criteria for protein identification were: two peptides with a Mascot individual ion score $>30$.

\section{Sandwich ELISA measurement of mouse IFN- $\lambda 3$ in organ homogenates}

Mouse liver and spleen homogenates were prepared as described in the Animal infections section $(i)$. Concentrations of IFN- $\lambda 3$ in homogenates was determined using Mouse IL28B/IFN-lambda 3 DuoSet (DY1789, R\&D Systems), according to the manufacturer's instructions. Briefly, wells of a 96-well plate were pre-coated with specific rat anti-mouse IL28B capture antibody and saturated with PBS, 1\% BSA (Reagent Diluent). $1 \mathrm{ml}$ of each organ 
homogenate was clarified by two successive centrifugation steps at 1,000 and $10,000 \times \mathrm{g}$, respectively. $30 \mu \mathrm{l}$ of sample supernatants from three distinct biological replicates were added to wells of the prepared ELISA plate, pre-filled with $70 \mu \mathrm{l}$ of Reagent Diluent. A standard curve was included, by loading in wells $100 \mu \mathrm{l}$ of 2-fold serial dilutions of recombinant mouse IL$28 \mathrm{~B}$, starting from $2 \mathrm{ng} / \mathrm{ml}$. After thorough washing steps, the detection antibody was then added, followed by the streptavidin-HRP conjugate, as specified by the manufacturer. Signals were revealed with Substrate and Stop Solutions (DY999 and DY994 respectively, all from R\&D Systems), and detected by reading the Absorbance at $450 \mathrm{~nm}$ using a TriStar LB941 device (Berthold technologies). For wavelength correction, readings at $590 \mathrm{~nm}$ were subtracted from the obtained values. Statistical analyses were performed using Student's two-tailed T-test on calculated concentrations.

\section{Bacterial RNA extraction and qRT-PCR}

RNA samples from Listeria grown to exponential or stationary phase at $37^{\circ} \mathrm{C}$ in rich medium or extracted from mouse spleens were extracted as previously described $(20,29)$ and treated with TURBO DNA-freetм kit (Ambion).

Bacterial cDNAs were generated with iScript cDNA Synthesis kit (Bio-Rad), following the manufacturer's protocol. Quantitative real-time PCR (qRT-PCR) was performed on a MyIQ device (Bio-Rad). Classical runs were 45 cycles with a hybridization temperature of $60^{\circ} \mathrm{C}$. Each reaction was performed in triplicate. $2 \mu \mathrm{l}$ of diluted cDNA samples were mixed with $10 \mu \mathrm{l}$ of $\mathrm{SYBR}_{\circledast}$ Green PCR master mix (Bio-Rad) and $0.25 \mathrm{pM}$ (each) forward and reverse primers in a final volume of $20 \mu \mathrm{l}$. A standard curve was generated for each primer pair by using three tenfold dilutions of a PCR product of defined concentration, to ensure that PCR efficiency was $100 \%$. Data were analyzed by the $\Delta \Delta \mathrm{Ct}$ method. Target gene expression data were normalized by the relative expression of a reference gene ( $16 S r R N A$ or $g y r A)$. The expression of the control Imo2845 gene, which encodes a putative transmembrane efflux protein, was not affected in vivo (20). The neat concentration of cDNA molecules in samples was calculated using standard curves. The specific primers pairs for each bacterial gene are specified in table S5.

\section{Transcriptome analysis of infected cells}

RNA from LoVo cells grown in 6-well plates and infected with either $\ln t A v 5+$ or $\ln t A$ - strains was extracted using the RNeasy Mini Kit (Qiagen). Three biological replicates were analyzed for each experimental condition. RNA quality was monitored on Agilent RNA Pico LabChips (Agilent Technologies, Palo Alto, CA). 300 ng of total RNA were analysed using the Affymetrix Human Gene1.0 ST Array (exon array), according to the GeneChip whole transcript sense target labeling assay manual, using the GeneChip WT cDNA Synthesis and amplification Kit and WT terminal labeling Kit. Human Gene 1.0 ST array interrogates 28,869 well-annotated genes with 764,885 distinct probes. The RNA was reverse transcribed using random primers tagged with a $\mathrm{T} 7$ promoter sequence. The second strand was synthesized, and the dsDNA was used as a template and linear amplified by T7 RNA polymerase. The cRNA was reverse transcribed using a mixture of dNTPs and dUTP and random primers. After RNaseH digestion, the ssDNA was fragmented with a combination of Uracil DNA glycosylase and apurinic/apyrimidinic endonuclease 1 . The fragmented ssDNA was end-labeled by terminal deoxynucleotidyl transferase with the Affymetrix proprietary DNA labeling reagent, which is covalently linked to biotin. The fragmented and labeled ssDNA was hybridized to arrays for 18 $\mathrm{h}$ and washed and scanned with the Affymetrix wash station and scanner. For data analysis, cell intensity files were generated with GeneChipOperating Software. Raw data were processed by the Robust Multichip Analysis (RMA) algorithm. A test for differential expression was performed between these two groups using the "lpe" package available on the R-open source 
software platform. Genes were considered to be significantly differentially expressed with a pvalue of $<0.05$ after multiple testing correction (Benjamin-Hochberg).

Complete data are deposited in the Gene Expression Omnibus Database (http://www.ncbi.nlm.nih.gov/geo/) with GEO accession number GSE26414.

\section{Human and mice RNA extraction and qRT-PCR}

RNA from infected and/or siRNA-treated human cells was extracted using RNeasy Mini Kit (Qiagen), using 1 column per well of a 6-well plate. For RNA extraction from mice kidneys, each organ was disrupted directly in $1 \mathrm{~mL}$ RLT buffer supplemented with $\beta$-mercaptoethanol using a GentleMACS Dissociator (Miltenyi Biotech). $100 \mu \mathrm{L}$ of organ homogenate was diluted in $250 \mu \mathrm{L}$ RLT buffer before loading on a RNeasy Mini column and processing to extraction as recommended by the manufacturer.

Genomic DNA was removed by treatment with TURBO DNA-freeтм kit (Ambion). cDNAs were generated from 1 to $2 \mu \mathrm{g}$ total RNA using the RT2 first strand kit (SABioSciences), and quantitative PCR was performed with RT2 qPCR Primer Assay (SABioSciences) following the manufacturer's protocol and the recommended two-step cycling program, on a MyIQ device (Bio-Rad). Each reaction was performed in triplicate. All human and mice qRT-PCR primers were pre-designed, validated RT2 qPCR primer pairs from SABioSciences. Data were analyzed by the $\Delta \Delta \mathrm{Ct}$ method. Target gene expression data were normalized to the relative expression of the GAPDH reference gene. Similar results were obtained when HPRT1 transcript was used as a reference.

\section{Chromatin immunoprecipitation experiments and site-specific PCR analysis}

This protocol was adapted from Boukarabila et al. (18). Chromatin inputs corresponding to 3.106 cells were used for each individual BAHD1 or H3K9Ac ChIP assay, and 1.106 cells for H3 ChIPs. All buffers were supplemented with Complete EDTA-free protease inhibitor cocktail tablets (Roche). Formaldehyde-fixed cells were washed in PBS and lysed in $10 \mathrm{mM}$ Tris, $\mathrm{pH}$ 8, $10 \mathrm{mM}$ EDTA, $0.5 \mathrm{mM}$ EGTA, $0.25 \%$ Triton X-100 for $5 \mathrm{~min}$ on ice. The nuclear pellets were recovered by brief centrifugation at $3,000 \mathrm{xg}$, and the soluble nuclear fraction was extracted with $250 \mathrm{mM} \mathrm{NaCl}, 50 \mathrm{mM}$ Tris $\mathrm{pH} 8,1 \mathrm{mM}$ EDTA, $0.5 \mathrm{mM}$ EGTA for $30 \mathrm{~min}$ on ice. After brief centrifugation at $16,000 \mathrm{xg}$, the chromatin pellets were resuspended in $10 \mathrm{mM}$ Tris $\mathrm{pH} 8,1 \mathrm{mM}$ EDTA, $0.5 \mathrm{mM}$ EGTA, 0.5\% SDS, and then sonicated with a Bioruptor (Diagenode) to shear chromatin to a final size of 150-600 bp. Extracts were quantified by A260nm measurement, and material quantities were adjusted accordingly. Samples were then diluted to obtain the following IP buffer composition: $150 \mathrm{mM} \mathrm{NaCl}, 10 \mathrm{mM}$ Tris $\mathrm{pH} 8,0.1 \%$ SDS, $1 \%$ Triton X-100, 0.1\% sodium deoxycholate, $1 \mathrm{mM}$ EDTA, $0.5 \mathrm{mM}$ EGTA. IP was carried out overnight at $4{ }^{\circ} \mathrm{C}$ with anti-BAHD1, -H3K9Ac or control -histone $\mathrm{H} 3$ antibodies. The immunocomplexes were recovered with Dynabeads Protein G (Invitrogen) added for 90 min and then washed 5 times in a succession of isotonic and saline buffers as described (18). After a final wash in $10 \mathrm{mM}$ Tris pH8, $1 \mathrm{mM}$ EDTA, $0.01 \%$ Igepal, bound material was eluted by the addition of water containing 10\% Chelex (Bio-Rad), followed by boiling for $10 \mathrm{~min}$ to reverse the crosslink. Samples were then incubated with proteinase $\mathrm{K}(100 \mu \mathrm{g} / \mathrm{mL})$ for $30 \mathrm{~min}$ at $55^{\circ} \mathrm{C}$ with some shaking, and then boiled for another $10 \mathrm{~min}$. Finally, the ChIP DNA fraction was separated from beads and Chelex matrix by centrifugation. The recovered supernatants were quantified by qRT-PCR, performed in triplicates in the same conditions as described above for bacterial cDNA quantifications; data analysis was performed with the $\Delta \Delta \mathrm{Ct}$ method. All primer sequences are given in table S5. The IFITM1-e1 primer pair amplified a 127 base-pair region located in the first exon of the gene, just downstream of the ISRE (Interferon Stimulation Response Element). CD44-GpG, IGF2-P3b and IFIT3-TS primer pairs were described 
previously $(6,30)$. All PCR efficiencies, calculated on serial dilutions of purified input DNA, were $90 \%-100 \%$. The qRT-PCR values obtained for the recruitment of the BAHD1 or H3K9Ac antibodies to chromatin were normalized using histone $\mathrm{H} 3$ antibody ChIP signals on the same chromatin extract as a reference.

\section{SOM text}

\section{Roles of type I, II and III interferons in listeriosis}

Type I interferons are beneficial for Listeria, while type II interferons are highly detrimental for this pathogen $(31,32)$. In the context of viral infections, IFN-III have been reported to substitute for type I IFN in specific tissues, such as epithelia $(33,34)$. We propose that LntAmediated expression of ISGs downstream of IFN-III may be beneficial for Listeria only at a certain time of the infection and in specific cells.

\section{Influence of the genetic background on the outcome of murine listeriosis}

To address the role of BAHD1 in murine listeriosis, we have generated $B A H D 1+/$ - mice. For technical reasons, we had to generate these mice in the C57BL/6 background, which is much more resistant to Listeria infection than the BALB/c background (19). This explains why CFU counts in organs were several orders of magnitude lower for experiments in $B A H D 1+/$ - mice and their WT littermates than in BALB/c mice (compare fig. 1B and $3 \mathrm{C}$ to fig. 3D). 


\section{Supporting Figures}

Fig. S1. Identification of $\ln t \boldsymbol{A}$ as a candidate virulence gene encoding a secreted protein.
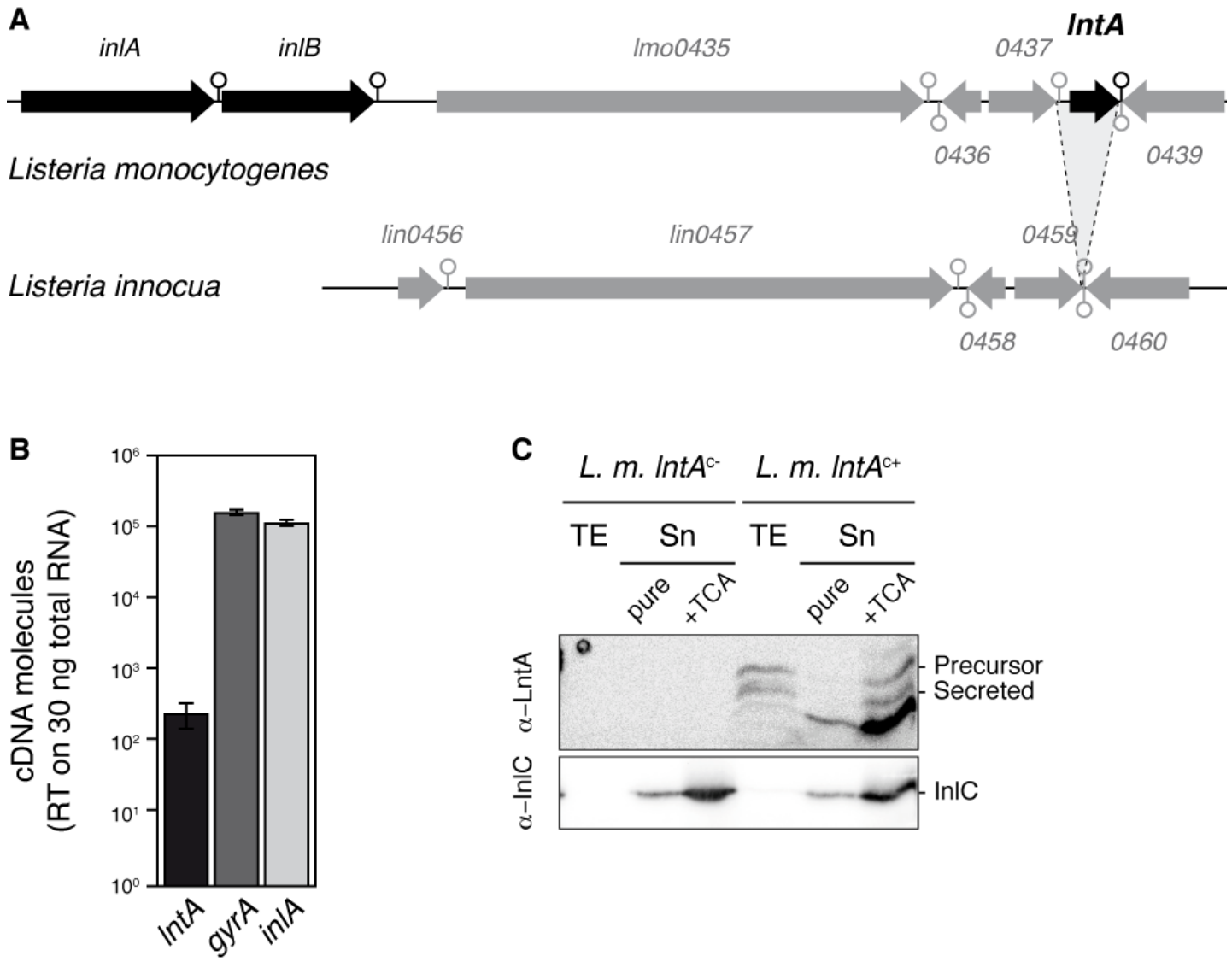

(A) The lntA/lmo0438 genome region in L. monocytogenes aligned with the corresponding region in the L. innocua genome. Genes with PrfA and $\sigma$ в boxes are in black. Imo0438 was selected as a candidate virulence gene by a genome-based in silico approach. Bioinformatic prediction of protein export signals had identified 138 genes encoding putatively secreted proteins in L. monocytogenes EGDe, e.g. proteins containing putative secretion signals and no domain for association at the bacterial surface (35). Further analysis of surface proteins allowed us to reduce this number to 121 (36). Among them, 22 genes were absent in the non-pathogenic $L$. innocua species (1), of which 6 known virulence genes, such as hly. We selected lmo0438 from the 16 remaining genes, because it localizes in the vicinity of the inlAB operon, which encodes major invasion proteins, and because lmo 0438 promoter region displays recognition boxes for PrfA and $\sigma$ B. These two regulators of virulence genes play key roles in the L. monocytogenes transition from saprophytic to pathogenic life $(37,38)$.

(B) lntA is expressed at very low levels by the L. monocytogenes EGDe strain grown in rich medium, when compared to the housekeeping gene gyrA or the virulence gene $i n l A$. IntA thus behaves as a category of Listeria virulence genes that are not expressed in broth or tissuecultured cells and are induced in vivo, such as inlJ (39). IntA, inlA and gyrA cDNA molecules were quantified by qRT-PCR, thanks to a standard curve performed on PCR products of known concentration. Data were normalized to $30 \mathrm{ng}$ of starting total RNA, extracted from WT Listeria grown to stationary phase in BHI medium, under microaeroby conditions. 
(C) $\operatorname{lnt} A$ encodes a secreted protein. L. monocytogenes constitutively expressing $\ln t A$ from a PHYPER promoter integrated on the bacterial chromosome $\left(\ln t A_{\mathrm{c}^{+}}\right)$or $L$. monocytogenes with the integrated empty vector (Int $A \mathrm{c}-)$, were grown at $37^{\circ} \mathrm{C}$ in $\mathrm{BHI}$ to a $\mathrm{OD} 600$ of 2 . Proteins from the bacterial total extracts (TE) and the supernatant fraction ( $\mathrm{Sn}$, pure or precipitated with TCA) were analyzed by immunoblot with antibodies against LntA and InlC, used as control of a secreted protein. The precursor protein $(\sim 23.4 \mathrm{kDa})$ is present in TE. The mature secreted LntA $(\sim 19,7 \mathrm{kDa})$ is present in the $\mathrm{Sn}$ fraction. 
Fig. S2. LntA folds into a compact helical structure.

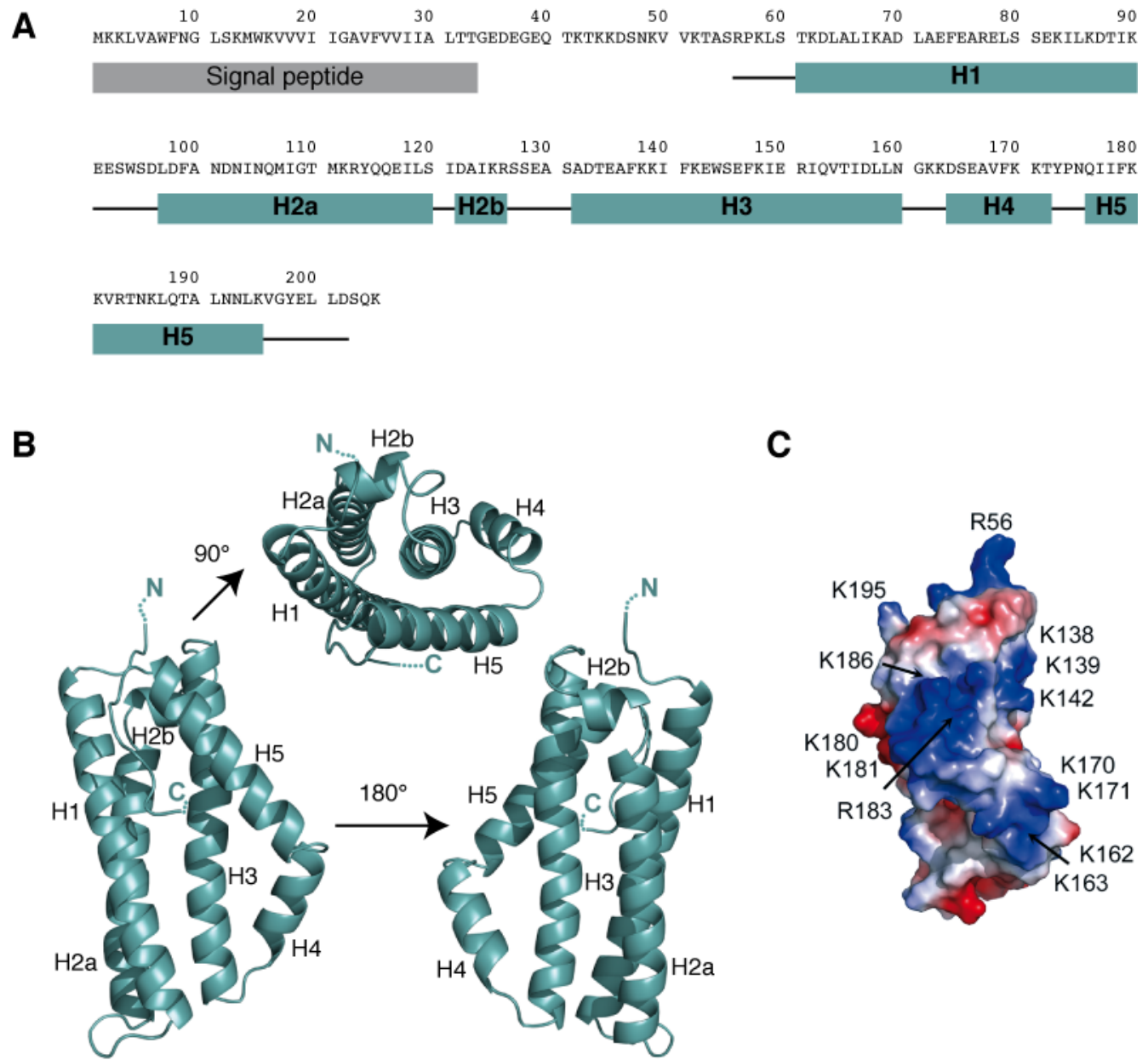

(A) LntA sequence. Positions of helices $\mathrm{H} 1$ to H5 in the secondary structure are shown below the protein sequence.

(B) Crystal structure of LntA56-202. We crystallized LntA34-205 and solved its structure by single anomalous dispersion (SAD) to $2.3 \AA$ resolution (data collection and structure refinement statistics can be found in table S7). The crystallographic model contains one LntA molecule per asymmetric unit and includes residues 56-202. The five $\alpha$-helices ( $\mathrm{H} 1$ to H5) compose a compact structure. Three long central helices $(\mathrm{H} 1, \mathrm{H} 2$ - formed by $\mathrm{H} 2 \mathrm{a}$ and $\mathrm{H} 2 \mathrm{~b}$ - and $\mathrm{H} 3$ ) form the core of the structure. The last two helices (H4-H5) form a right angle along the axis. Residues 34-55 and 203-205 could not be traced in the electron density map and are thus represented as dots. Structure data are deposited at the PDB (http://www.wwpdb.org/), ID \#2x14, structure factor file \#r2x14sf.

(C) Surface representations of LntA with positive (in red) and negative (in blue) charges. In addition to numerous basic residues, an acidic patch decorates the bottom of the structure. 
Fig. S3. Deletion or constitutive expression of $\ln t A$ does not alter bacterial invasion of host cells.

A

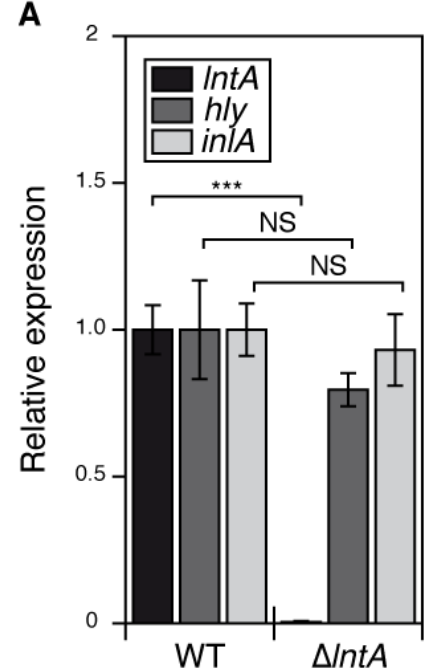

B

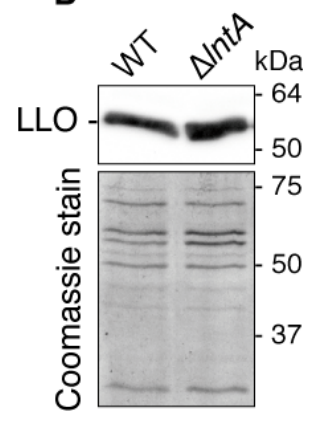

\begin{tabular}{c}
\hline Post-infection: \\
$\square 2 \mathrm{~h}$ \\
$\square 24 \mathrm{~h}$ \\
\hline
\end{tabular}

C

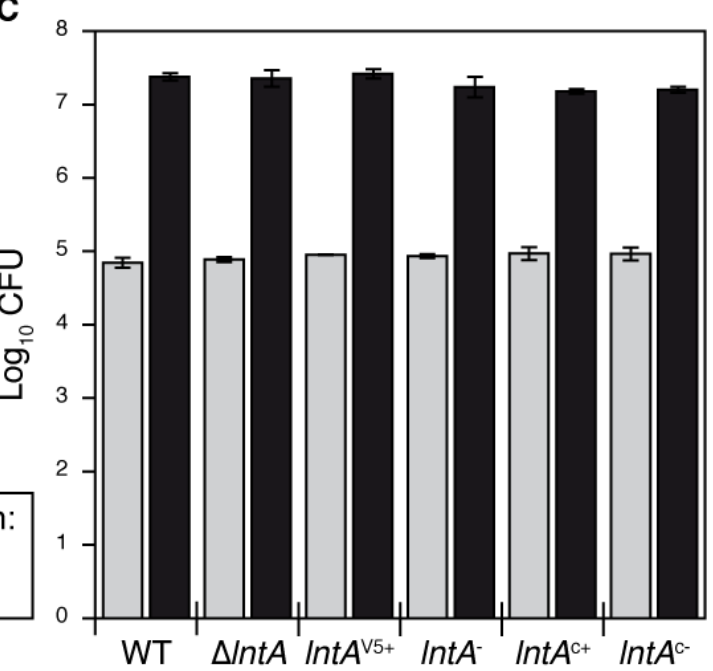

(A) Deletion of $\operatorname{lnt} A$ does not affect the expression of inlA and hly virulence genes. $\ln t A$, hly and inlA mRNA levels were quantified by qRT-PCR on total RNA from WT EGDe or $\Delta l n t A$ isogenic strains. Data were normalized to gyrA mRNA and levels in WT. Error bars indicate standard deviation. Relative expression values of hly and inlA in $\Delta l n t A$ strain are not statistically different (NS) from WT levels, according to a two-tailed T-test. $* * *, p<0,001$.

(B) Deletion of $\ln t A$ does not affect the secretion of the $h l y$ product, listeriolysin O (LLO). WT and $\Delta l n t A$ Listeria strains were grown in BHI to stationary phase. Proteins from culture supernatants were precipitated with TCA, then separated by SDS-PAGE on two identical gels. One gel was used for an immunoblot with antibodies against LLO (upper panel). The second gel was stained with coomassie (lower panel).

(C) Bacterial intracellular multiplication in LoVo cells is not altered by depletion or constitutive expression of $\ln t A$. The number of intracellular bacteria in infected LoVo cells was quantified $2 \mathrm{~h}$ or $24 \mathrm{~h}$ post infection by a gentamicin survival assay. Int $A$-expressing or non-expressing L. monocytogenes strains displayed no significant difference in intracellular replication in host cells. 
Fig. S4. LntA colocalizes with BAHD1 in the nucleus of human living cells.
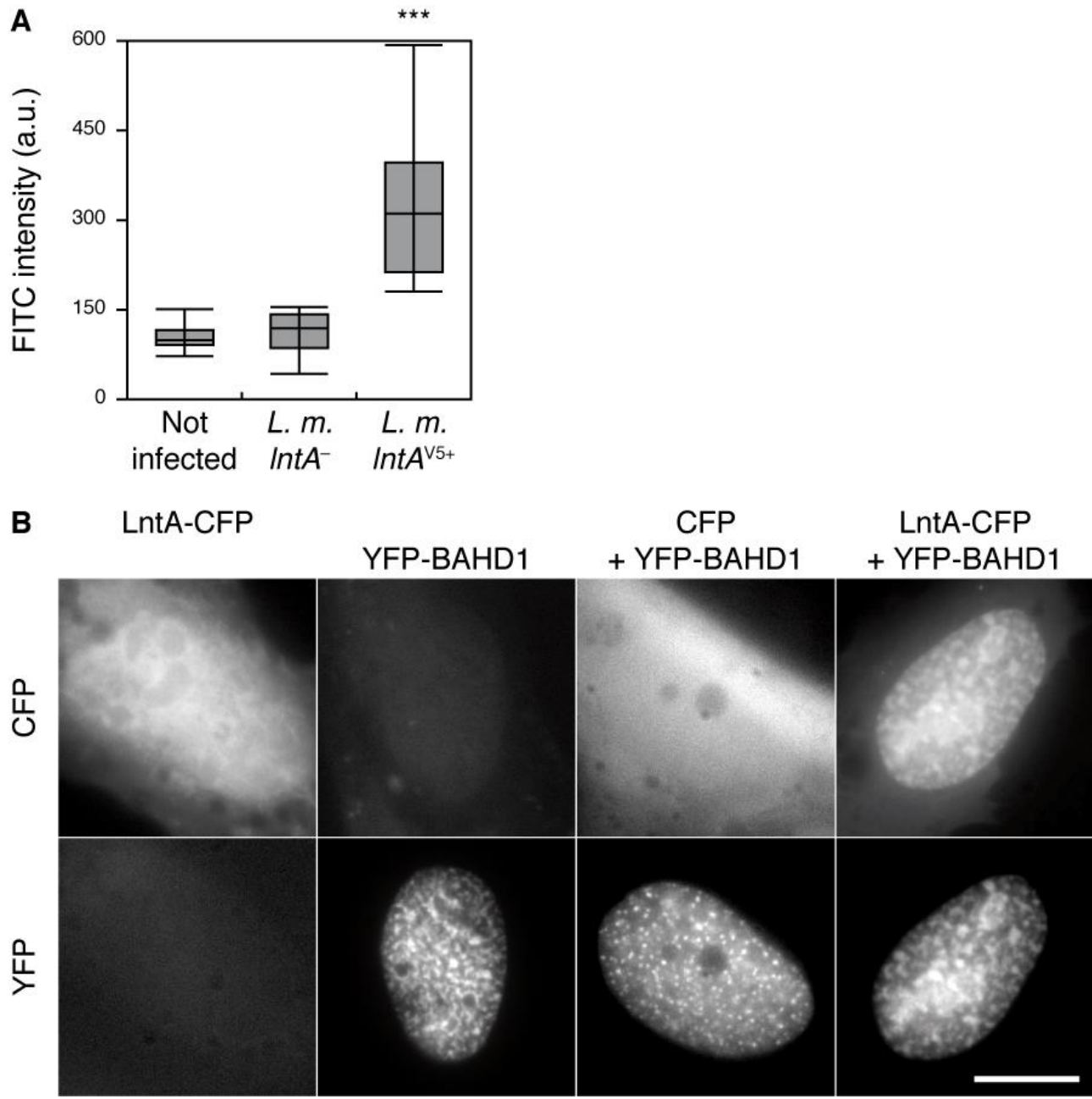

(A) Quantification of the LntA-V5 signal in the nucleus of human infected cells. C3SV40 fibroblasts were infected or not for $22 \mathrm{~h}$ with $\operatorname{lntA}$ - or $\operatorname{lntAv5}+$ bacteria. The LntA-V 5 protein was detected by immunofluorescence with FITC-coupled $\alpha$-V5 antibody. FITC fluorescence signals were quantified in the nuclei of cells. The box-whisker plot indicates quartiles and median values. a.u., arbitrary units; ${ }^{* * *}, \mathrm{p}<0.001$ (two-tailed T-test). The V5 staining was significantly more intense in nuclei of $\ln t A-V 5+$ infected cells compared to non-infected cells or cells infected with the $\ln t A$-deficient strain.

(B) Ectopically expressed LntA colocalizes with BAHD1-induced heterochromatin foci in living cells. $\mathrm{pEYFP}-B A H D 1$ was co-transfected into C3SV40 cells with either $\mathrm{pE}-\mathrm{mCFP}$ - $\ln t A$ or $\mathrm{pE}-\mathrm{m} C F P$. Fluorescent CFP (upper panels) or YFP (lower panels) signals were monitored in mono- or co-transfected living cells. Scale bars, $5 \mu \mathrm{m}$. 
Fig. S5. Expression of interferon genes and ISGs in response to Listeria infection.
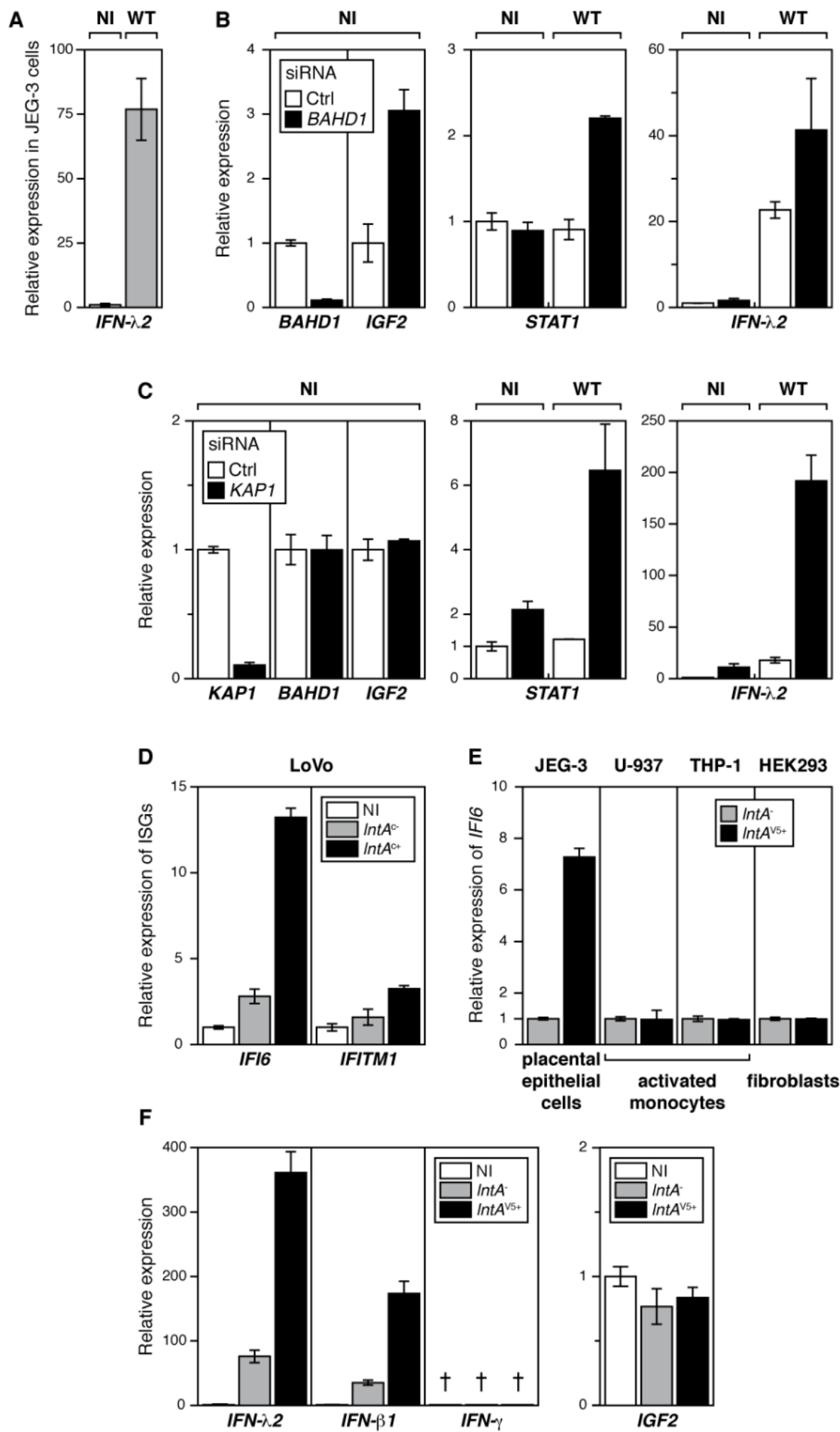

(A) L. monocytogenes induces the expression of IFN-III in placental epithelial JEG-3 cells. qRT-PCR analysis of IFN- $\lambda 2$ expression in response to Listeria infection of JEG-3 cells infected for $16 \mathrm{~h}$ with WT L. monocytogenes (gray), compared to non-infected cells (NI, white). All data (here and in panels B-F) were analyzed with $\triangle \triangle \mathrm{Ct}$ method and normalized to GAPDH housekeeping gene transcript level. 
(B) Quantification of BAHD1, IGF2, STAT1 and IFN- 22 expression levels in control or BAHD1 siRNA-treated LoVo cells. Efficiency of the 72-h siRNA treatment was assessed by qRT-PCR. As we reported previously in HEK293 cells (6), IGF2 expression increased upon BAHD1 knockdown in LoVo cells. As we showed for other ISGs (fig. 2B), STAT1 and IFN- 22 expression levels were higher upon BAHDl knockdown in 16-h Listeria-infected cells.

(C) Quantification of $K A P 1, B A H D 1, I G F 2, S T A T 1$ and $I F N-\lambda 2$ expression levels in control or $K A P 1$ siRNA-treated LoVo cells. KAP1 siRNA affected neither $B A H D 1$, nor $I G F 2$ expression. $S T A T 1$ and $I F N-\lambda 2$ expression levels increased upon KAPI knockout, as for any other ISG (fig. 2B).

(D) Non-tagged LntA up-regulates ISGs in infected cells when expressed from the chromosome. IFI6 and IFITMI mRNA levels were estimated by qRT-PCR on total RNA from LoVo epithelial cells infected for $22 \mathrm{~h}$ with either the $\ln t A$-defficient $\ln t A \mathrm{c}$ - strain, or the isogenic $\ln t A_{\mathrm{c}+}$ strain that expressed constitutively $\ln t A$ from a chromosomal locus.

(E) LntA up-regulates ISGs only in infected cells of epithelial origin. JEG-3, U-937, THP-1 or HEK293 cells were infected with the $\ln t A$ - or $\ln t A \mathrm{v} 5+$ strains for $22 \mathrm{~h}$. mRNA quantifications and normalizations were as above.

(F) Right. The expression of $I F N-\lambda 2$ and $-\beta 1$ is stimulated by LntA, as observed for other ISGs. LoVo cells were infected with the $\ln t A$ - or $\ln t A \mathrm{v} 5+$ strains for $16 \mathrm{~h}$, or not infected. mRNA quantifications and normalizations were as above. Note that the expression of IFN- $\gamma$ remained below detection limits $(\dagger)$, as expected in a non-hematopoietic cell lineage.

Left. Quantification of IGF2 expression levels in infection experiments. LoVo cells infected for $16 \mathrm{~h}$ with either $\ln t A$ - or $\ln t A \mathrm{v} 5+$ Listeria monocytogenes were not affected for the expression of $I G F 2$, compared to non-infected cells. 
Fig. S6. Tandem-affinity purification of the HPT-BAHD1 associated complex.

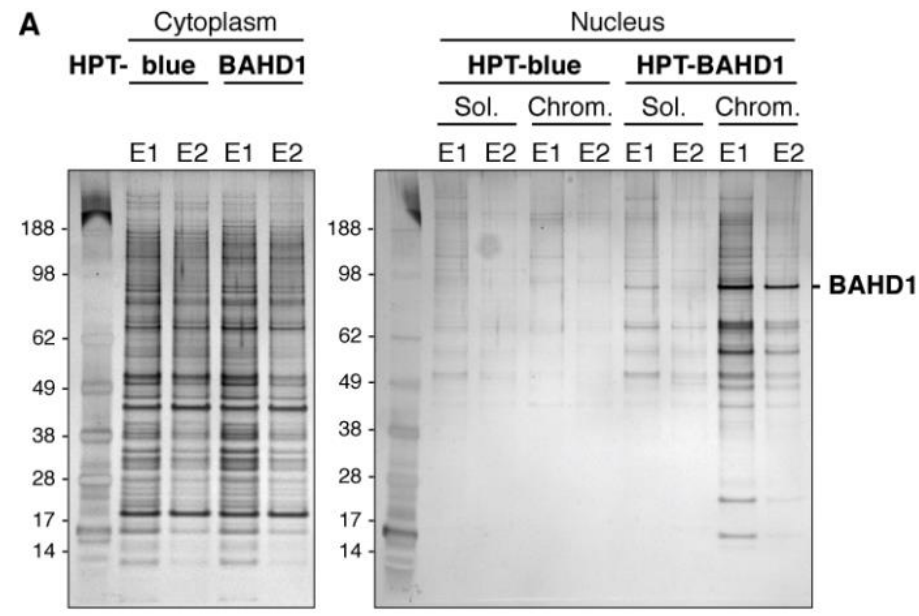

B

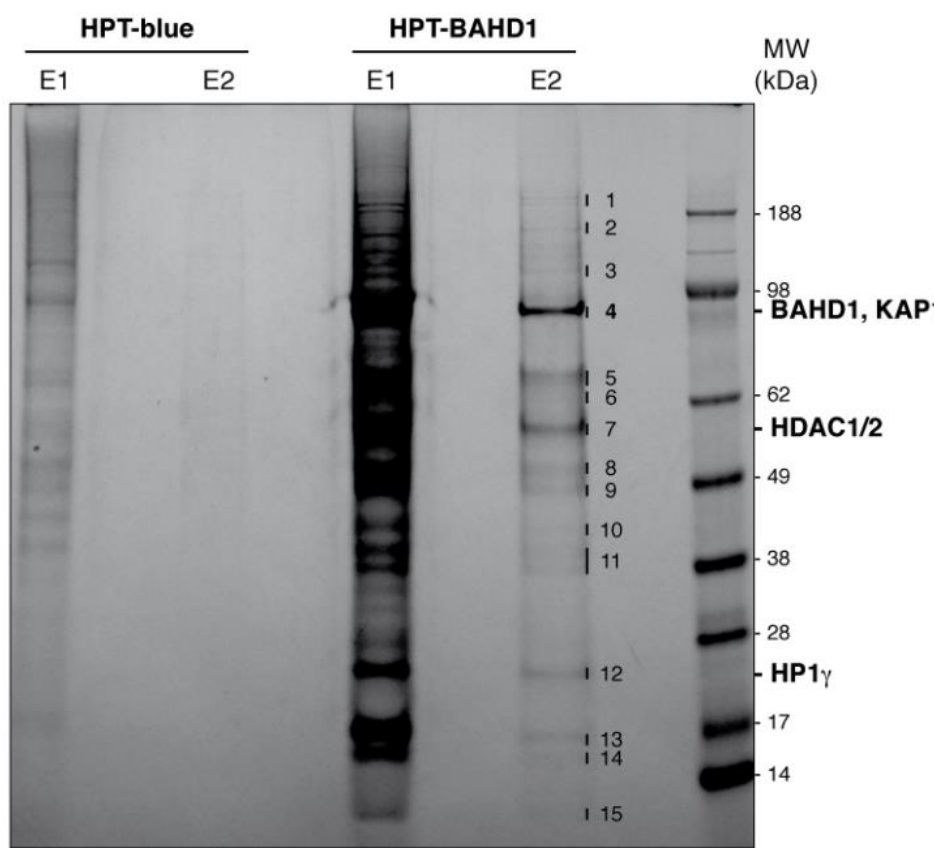

(A) BAHD1 is specifically enriched in the chromatinassociated fraction.

Cytoplasmic, soluble nuclear (Sol.) or solubilized chromatin (Chrom.) extracts of HEK293HPT-BAHD1 cells or control HPT-blue cells were separated by two successive steps of chromatography. Eluates were separated by gradient SDSPAGE, and stained with Coomassie colloidal staining. E1, eluted fractions from the antiprotein $\mathrm{C}$ resin (1/100 total); E2, eluted fraction from the nickelsepharose resin (1/10 total).

Note that affinity-purified HPTBAHD1 is specific of the chromatin extracts. In other fractions, recovered material is mostly non-specific, as highlighted by the comparison with HPT-blue lanes. The HPT tag consists of a His6, protein $\mathrm{C}$ epitope, TEV cleavage site sequence.

(B) Preparative gel for the analysis of the HPT-BAHD1-associated complex by mass spectrometry. 1/4th of the chromatin-specific E1 and E2 eluates were separated by gradient SDS-PAGE, and stained with Coomassie colloidal staining. Bands 1-15 from the two-step purified, chromatin-associated complex were cut out and proteins were identified by LC-MSMS. Those containing BAHD1, KAP1, HDAC1/2 and HP1 $\gamma$ are highlighted. 
Fig. S7. Proposed model for BAHD1/LntA-mediated regulation of ISGs.

A

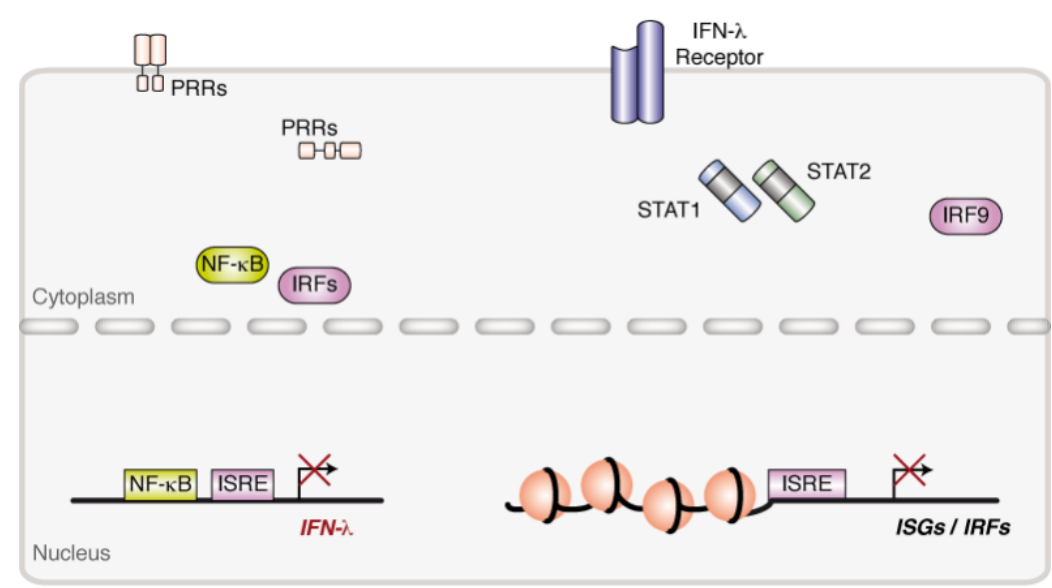

B
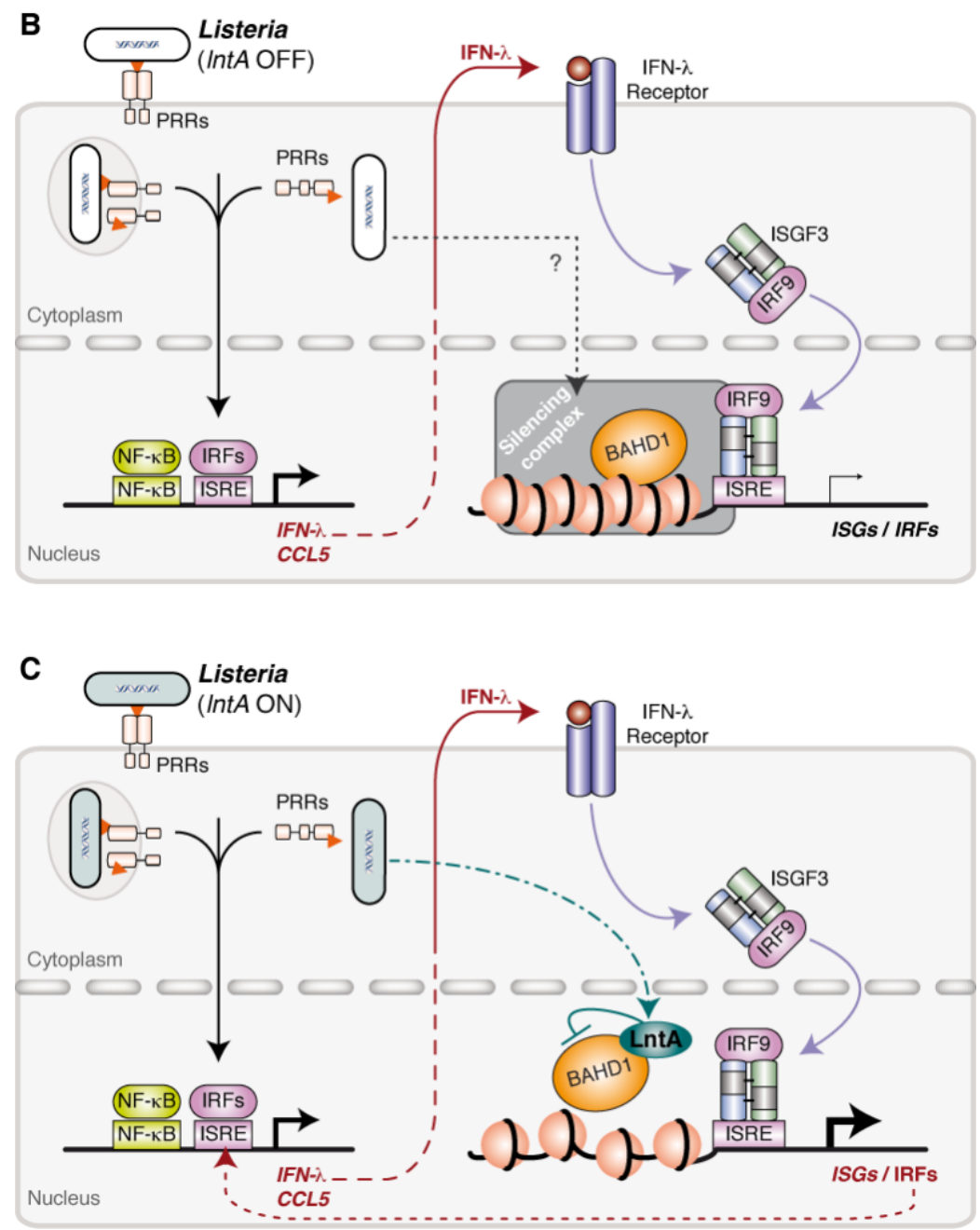

(A) Interferon genes and ISGs are not expressed in resting cells.

(B) During infection of epithelial cells by L. monocytogenes, the recognition of bacterial molecules (MAMPs, Microbial Associated Molecular Patterns) by Patterns Recognition Receptors (PRRs) activates NF- $\mathrm{KB}$ and IRF transcriptional factors, which translocate into the nucleus and induce expression of type III, and to a lesser extend type I, interferons, as well as 
of other NF- $\kappa \mathrm{B} / \mathrm{IRF}$-dependent genes, such as CCL5. Subsequently, IFN- $\lambda$ s are secreted, activate their receptor and the downstream JAK/STAT pathway, leading to translocation of ISGF3 (e.g. STAT1/2-IRF9 complex) transcription factor into the nucleus. However, in response to a still non-identified infection-triggered signaling pathway, the BAHD1 silencing complex down-regulates ISGs by compacting chromatin.

(C) Under specific conditions, i.e. in specific tissues and at a given time point during infection, Listeria secretes LntA, which enters the host cell nucleus. Binding of LntA to BAHD1 destabilizes the repressive complex and enhances expression of ISGs and IRFs genes that further amplify $I F N-\lambda$ and $C C L 5$ expression.

DNA binding sites for IRFs, NF- $\kappa$ B and ISGF3 are shown by boxes. Chromatin nucleosomes are shown by circles. $\square$ MAMPs. IRF, Interferon Regulatory Factor; ISRE, Interferon Stimulation Response Element; ISGF3, Interferon-Stimulated Gene Factor-3. 
Fig. S8. Bacterial intracellular multiplication in LoVo cells is not altered by IFN- $\lambda$-stimulation.

24-h Pre-stimulation

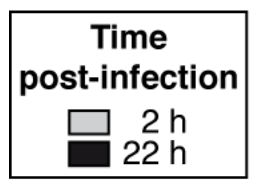

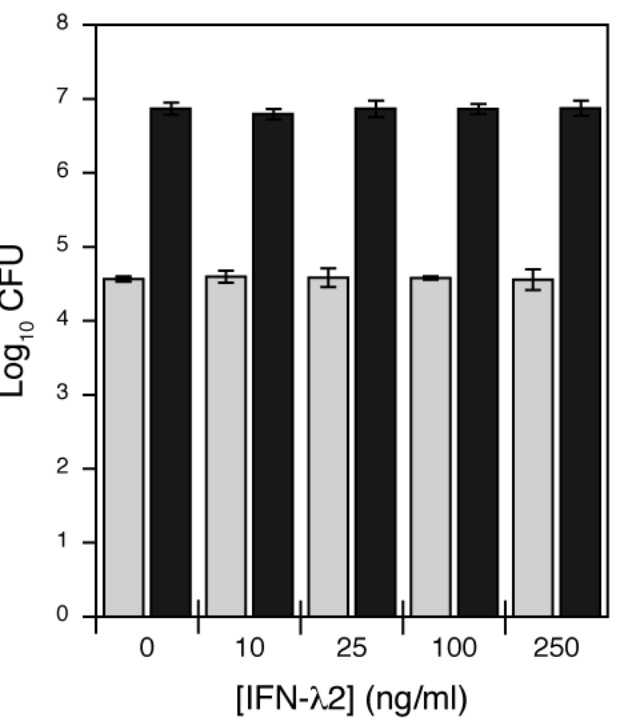

Concomitant stimulation

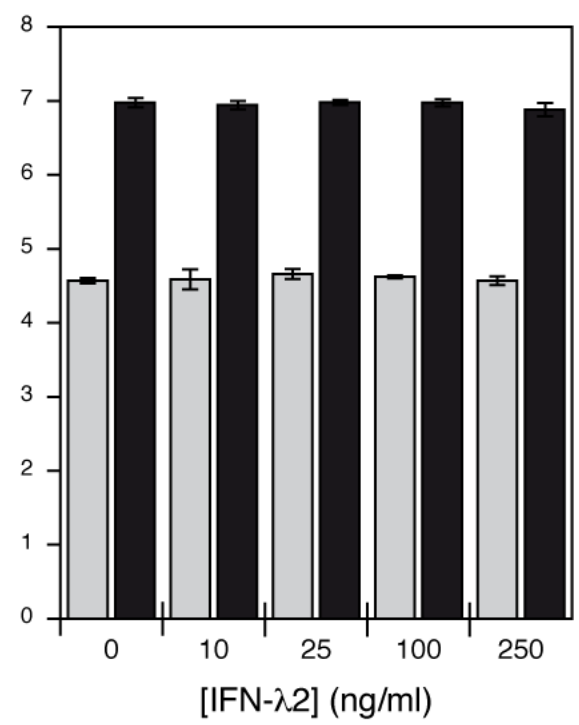

LoVo cells were pre-stimulated $24 \mathrm{~h}$ before infection with WT L. monocytogenes (left) or stimulated together with infection (right), with increasing concentration of purified recombinant IFN- $\lambda 2$. Cell response to IFN- $\lambda 2$ was checked in parallel by quantifying representative ISG transcripts by qRT-PCR (not shown). The number of intracellular bacteria in infected cells was not statistically different, with or without IFN- $\lambda 2$ treatment. 
Fig. S9. Verification of the $B A H D 1 \mathrm{KO}$ allele.

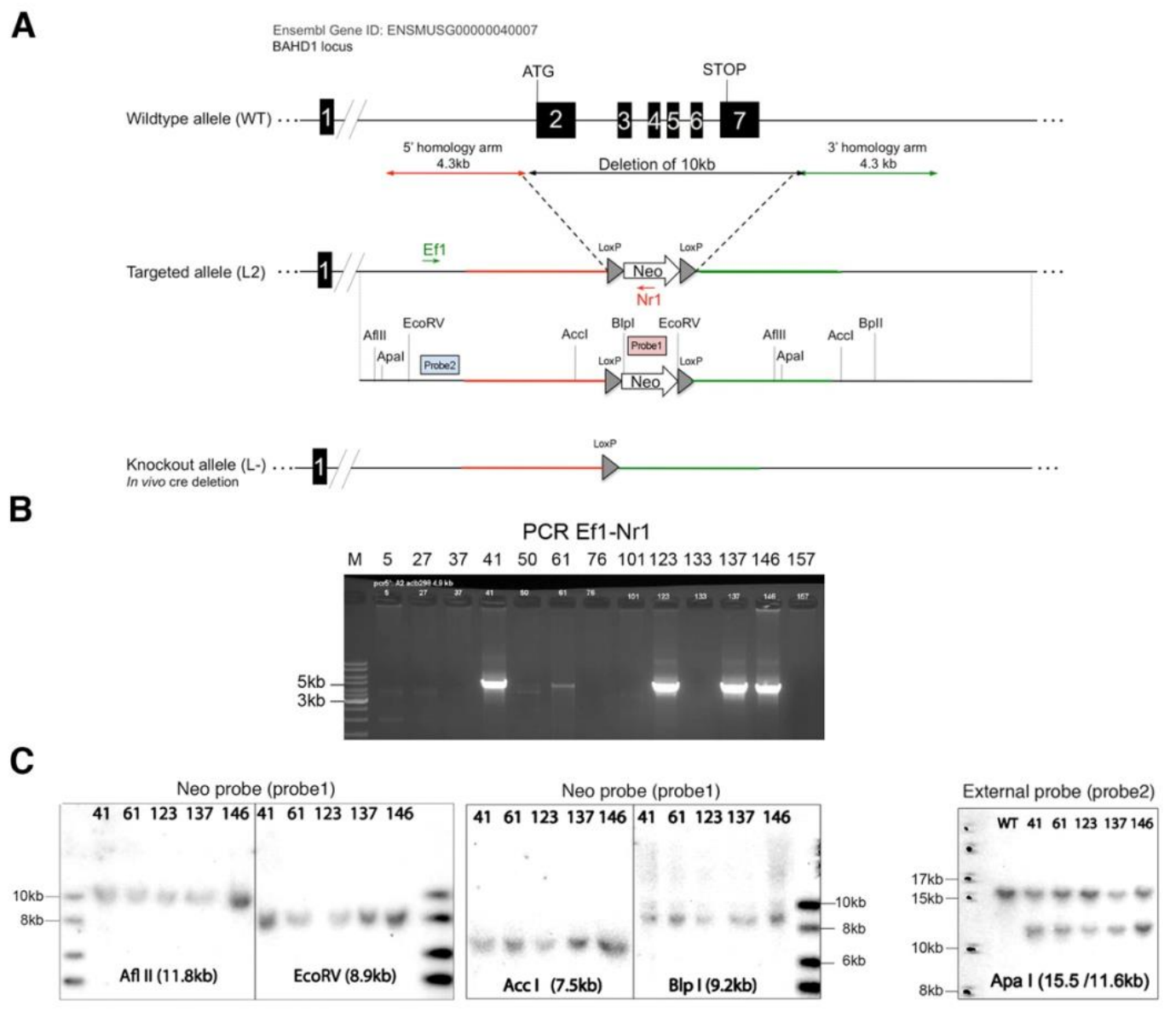

(A) The BAHD1 KO allele was generated by homologous recombination replacement of the entire coding region of the BAHD1 allele $(10 \mathrm{~kb})$ with a neomycin cassette $(\mathrm{Neo})$ flanked by loxP sites, leading to the targeted allele (L2). The Neo cassette was excised upon expression of the Cre recombinase in vivo, leading to the knockout allele (L).

(B) PCR amplification using Ef1 and Nr1 primers identified 5 positive ES clones.

(C) Positive clones were further tested by Southern blotting using a Neo probe (probe1) or an external probe (probe2). The positions of the restriction sites and probes used are shown in (A). 
Fig. S10. Genotyping of $B A H D 1+/$ mice.

A

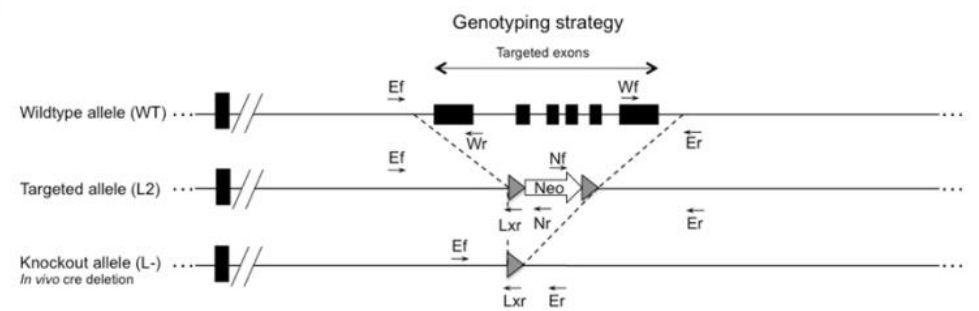

B
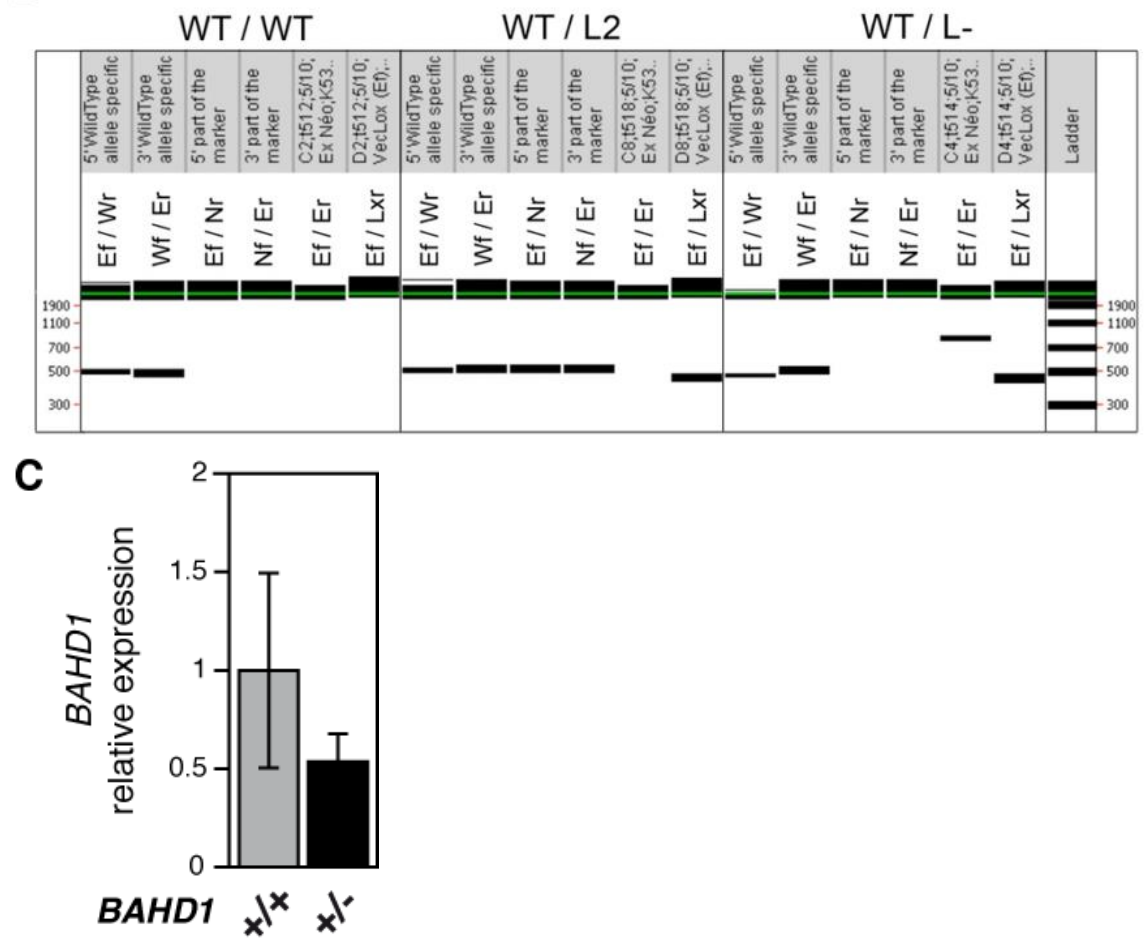

(A) The map describes the position of the primers used for genotyping for each possible allele. (B) A representative genotyping picture obtained with LabChip ${ }^{\circledR} 90$ microfluidic apparatus. The primers used and size of expected products are shown in table S5.

(C) Expression of BAHD1 mRNA in organs of $B A H D 1+/$ - mice and their BAHD1+/+ littermates. $B A H D 1$ mRNA was quantified by qRT-PCR on total RNA extracted from mice kidneys. Data were analyzed with the $\triangle \triangle \mathrm{Ct}$ method and normalized to GAPDH housekeeping gene transcript level. 
Fig. S11. Both deletion and constitutive expression of IntA in Listeria decrease bacterial burden during murine systemic listeriosis.

A Spleen

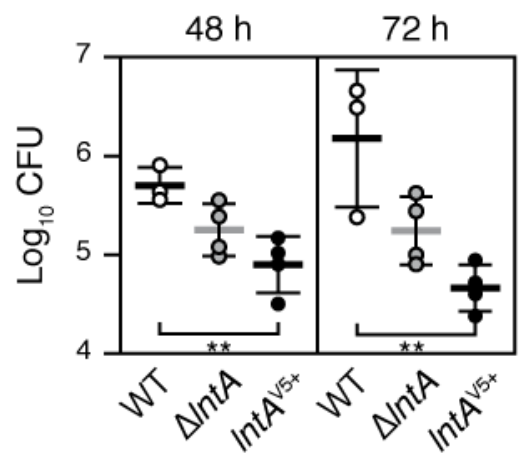

B Liver

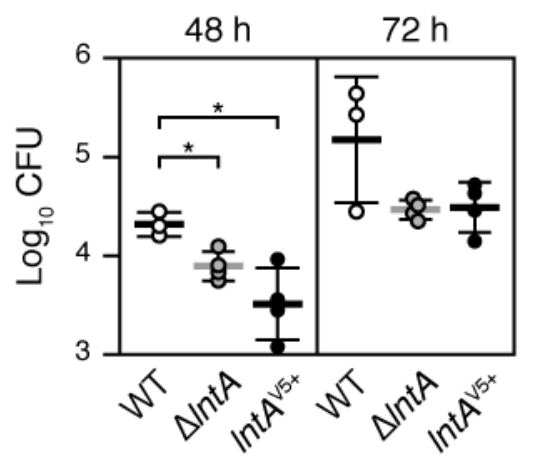

Mice were infected intravenously with WT L. monocytogenes, $\Delta \operatorname{lnt} A$ or $\ln t A \mathrm{v} 5+$ strains. Colony forming units (CFU) per organ were numerated at $48 \mathrm{~h}$ and $72 \mathrm{~h}$ post-infection in the spleens (A) and livers (B) of infected animals. Error bars indicate standard deviations. Statistically significant differences according to a two-tailed T-test were highlighted. ${ }^{*}, \mathrm{p}<0.05 ;{ }^{* *}, \mathrm{p}<$ 0.01 .

The colonization of organs by $\Delta \operatorname{lnt} A$ bacteria and by bacteria constitutively expressing $\ln t A-V 5$ from a multicopy plasmid was decreased compared to WT, both at $48 \mathrm{~h}$ (like in fig. 1B, right) and at $72 \mathrm{~h}$ post infection. 


\section{Supporting Tables}

Table S1. Bacterial strains.

\begin{tabular}{|c|c|c|}
\hline Name & Characteristics & Reference \\
\hline BUG1600 & Listeria monocytogenes EGDe & ATCC BAA-679 (1) \\
\hline BUG2214 & EGDe $\Delta p r f A$ & $(40)$ \\
\hline BUG2215 & EGDe $\Delta \operatorname{sig} B$ & $(40)$ \\
\hline BUG2168 & EGDe $\Delta \ln l A$ & This work \\
\hline BUG2169 & EGDe $\Delta \ln l A$ & This work \\
\hline BUG2384 & EGDe $[\mathrm{pP} 1-\ln t A-V 5] \quad\left(\right.$ referred to as $\left.\ln t A \mathrm{v} 5^{+}\right)$ & This work \\
\hline BUG2466 & EGDe $\Delta \ln l A[\mathrm{pP} 1] \quad\left(\right.$ referred to as $\left.\ln t A_{-}\right)$ & This work \\
\hline BUG2820 & EGDe $\Delta \ln l A:$ pPL2 $\quad\left(\right.$ referred to as $\left.\ln t A_{\mathrm{c}-}\right)$ & This work \\
\hline BUG2822 & EGDe $\Delta \operatorname{lnt} A$ :pPL2-PHYPER-5'-UTRhly-lntA (referred to as $\left.\ln t A_{\mathrm{c}^{+}}\right)$ & This work \\
\hline
\end{tabular}

Table S2. Plasmids.

\begin{tabular}{lllr}
\hline Name & Description & Tag (position) & Reference \\
\hline pBUG942 & pP1 multicopy plasmid with PPRT promoter & & $(3)$ \\
pBUG2383 & pP1-lntA-V5 & V5 (C-ter) & This work \\
pBUG2387 & pcDNA3.1/V5-His-TOPO-lntA34-205 & V5-His (C-ter) & This work \\
pBUG2388 & pcDNA3.1/V5-His-TOPO-mCFP & V5-His (C-ter) & $(6)$ \\
pBUG2389 & pcDNA3.1/V5-His-TOPO-BAHD1 & V5-His (C-ter) & $(6)$ \\
pBUG2392 & pE-mCFP-N1-lntA34-205 & mECFP (C-ter) & This work \\
pBUG2393 & pB27-lntA34-205 & LexA (C-ter) & This work \\
pBUG2397 & pET41a-lntA34-205 & GST-His (N-ter) & This work \\
pBUG2507 & pMAD- lntA & & This work \\
pBUG2809 & pPL2-PHYPER-5'-UTRhly-lntA & & This work \\
pPL2 & Listeria monocytogenes site-specific integration vector & & $(4)$ \\
pGEX-lntA & [pGEX-4T-1] lntA34-205 & GST (N-ter) & This work \\
pAG834 & pcDNA5/FRT-HPT-blue & HPT (N-ter) & (5) \\
pAG978 & pcDNA5/FRT/TO-HPT-blue & HPT (N-ter) & This work \\
pAG1190 & pcDNA5/FRT/TO-HPT-BAHD1 & HPT (N-ter) & This work \\
\hline
\end{tabular}


Table S3. Bacterial entry in LoVo cells is independent of $\operatorname{lnt} A$ expression and is not altered by IFN- $\lambda 2$ treatment.

(A) Invasiveness of LoVo cells by IntA-expressing or non-expressing L. monocytogenes.

The percentage of entry in epithelial cells for a MOI of 20 was quantified by a gentamicin survival assay. Results are expressed as percentage of the inoculum that survived the gentamicin test. Means \pm standard deviations (SD) were calculated on three biological replicates. This assay was reproduced independently at least three times and gave similar results. There was no significant difference between the strains in efficiency of entry.

\begin{tabular}{|c|c|c|c|c|c|c|}
\hline & WT & $\Delta \ln t A$ & $\ln t A \mathrm{v} 5+$ & $\ln t A$ & $\ln t A_{c^{+}}$ & $\ln t A \mathrm{c}-$ \\
\hline $\begin{array}{l}\text { Inoculum } \\
(\mathrm{CFU} / \mathrm{ml})\end{array}$ & 9.1106 & 9.7106 & $1.010_{7}$ & 9.3106 & 1.0107 & 9.5106 \\
\hline $\begin{array}{l}\% \text { entry } \\
(\text { mean } \pm \mathrm{SD})\end{array}$ & $\begin{array}{c}0.78 \\
\pm 0.12\end{array}$ & $\begin{array}{c}0.80 \\
\pm 0.06\end{array}$ & $\begin{array}{c}0.85 \\
\pm 0.01\end{array}$ & $\begin{array}{c}0.92 \\
\pm 0.05\end{array}$ & $\begin{array}{c}0.93 \\
\pm 0.19\end{array}$ & $\begin{array}{c}0.99 \\
\pm 0.19\end{array}$ \\
\hline
\end{tabular}

(B) Invasiveness of IFN- $\lambda$-treated LoVo cells by $L$. monocytogenes.

Cells were incubated with increasing concentrations of IFN- $\lambda 224 \mathrm{~h}$ before being infected with WT bacteria. The level of entry for an inoculum of 5.106 bacteria $(\mathrm{MOI}=20)$ was quantified by a gentamicin survival assay. Results are expressed as above. This assay was reproduced twice and gave similar results. Pre-treatment of cells with IFN- $\lambda 2$ had no significant effect on bacterial entry into epithelial cells.

\begin{tabular}{lccccc}
\hline IFN- $\boldsymbol{\lambda} \mathbf{2}(\mathbf{n g} / \mathbf{m l})$ & - & $\mathbf{1 0}$ & $\mathbf{2 5}$ & $\mathbf{1 0 0}$ & $\mathbf{2 5 0}$ \\
\hline \% entry & 0.81 & 0.89 & 0.87 & 0.92 & 0.83 \\
$($ mean $\pm \mathrm{SD})$ & \pm 0.07 & \pm 0.16 & \pm 0.24 & \pm 0.05 & \pm 0.29 \\
\hline
\end{tabular}


Table S4. Transcriptome data - genes activated by LntA in infected LoVo cells.

The following table recapitulates the list of differentially modulated transcripts from Affymetrix Human Gene 1ST genechip data, in LoVo cells infected either with $\ln t A v 5+$ or $\ln t \mathrm{~A}-$ strains. Only 324 up-regulated transcripts with a significantly different level in the comparison of samples after Benjamini Hochberg $p$-value adjustment $(p<0,05)$ and showing a minimum of 1.2 fold difference were considered. Complete data are available in the Gene Expression Omnibus Database (http://www.ncbi.nlm.nih.gov/geo/) with GEO accession number GSE26414. FC, Fold change (lntA-V5+/lntA-); p-value, adjusted p-value (BenjaminiHochberg).

Genes belonging to the ISG regulon are highlighted as follows: green, interferon gene; yellow, annotated ISG from the interferome database (http://www.interferome.org); orange, annotated ISG from a manual bibliography search in the PubMed database (http://www.ncbi.nlm.nih/gov/pubmed); pink, predicted ISGs from the cisRED database (http://www.cisred.org). 39 genes with a fold change above 2 are highlighted in bold letterings.

\begin{tabular}{|c|c|c|c|c|}
\hline Assignment & Gene name & Definition & FC & p-value \\
\hline NM_003641 & IFITM1 & interferon induced transmembrane protein $1(9-27)$ & 4.03 & $\mathbf{0}$ \\
\hline NM_002053 & GBP1 & guanylate binding protein 1 , interferon-inducible, $67 \mathrm{kDa}$ & 3.63 & $\mathbf{0}$ \\
\hline NM_002535 & OAS2 & 2-5-oligoadenylate synthetase 2, 69 & 3.53 & $\mathbf{0}$ \\
\hline NM_014070 & C6orf15 & chromosome 6 open reading frame 15 & 3.48 & 1.79E-12 \\
\hline NM_004585 & RARRES3 & retinoic acid receptor responder (tazarotene induced) 3 & 3.18 & 1.08E-11 \\
\hline NM_172138 & IL28A & interleukin 28A (interferon, lambda 2) & 3.14 & $\mathbf{0}$ \\
\hline NM_002463 & MX2 & myxovirus (influenza virus) resistance 2 (mouse) & 3.05 & $\mathbf{0}$ \\
\hline NM_006820 & IFI44L & interferon-induced protein 44-like & 3.03 & 6.58E-10 \\
\hline NM_152703 & SAMD9L & sterile alpha motif domain containing 9-like & 2.99 & 1.92E-12 \\
\hline NM_017523 & XAF1 & XIAP associated factor-1 & 2.79 & $\mathbf{0}$ \\
\hline NM_172139 & IL28B & interleukin 28B (interferon, lambda 3) & 2.77 & $\mathbf{0}$ \\
\hline NM_004688 & NMI & N-myc (and STAT) interactor & 2.66 & $\mathbf{0}$ \\
\hline NM_080424 & SP110 & SP110 nuclear body protein & 2.53 & $\mathbf{0}$ \\
\hline NM_004184 & WARS & tryptophanyl-tRNA synthetase & 2.51 & $\mathbf{0}$ \\
\hline NM_001565 & CXCL10 & chemokine (C-X-C motif) ligand 10 & 2.48 & $3.24 E-05$ \\
\hline NM_016582 & SLC15A3 & solute carrier family 15 , member 3 & 2.48 & $\mathbf{0}$ \\
\hline NM_172140 & IL29 & interleukin 29 (interferon, lambda 1) & 2.43 & $\mathbf{0}$ \\
\hline NM_006472 & TXNIP & thioredoxin interacting protein & 2.30 & $\mathbf{0}$ \\
\hline NM_003335 & UBE1L & ubiquitin-activating enzyme E1-like & 2.28 & 1.12E-05 \\
\hline NM_002985 & CCL5 & chemokine (C-C motif) ligand 5 & 2.27 & $5.36 \mathrm{E}-10$ \\
\hline NM_001255 & CDC20 & cell division cycle 20 homolog (S. cerevisiae) & 2.22 & 1.29E-12 \\
\hline NM_005516 & HLA-E & major histocompatibility complex, class I, E & 2.22 & 5.17E-06 \\
\hline NM_005030 & PLK1 & polo-like kinase 1 (Drosophila) & 2.22 & 9.57E-12 \\
\hline NM_080657 & RSAD2 & radical S-adenosyl methionine domain containing 2 & 2.22 & $\mathbf{0}$ \\
\hline NM_005533 & IFI35 & interferon-induced protein 35 & 2.20 & $\mathbf{0}$ \\
\hline NM_003265 & TLR3 & toll-like receptor 3 & 2.20 & 7.75E-06 \\
\hline AJ583822 & USP41 & ubiquitin specific peptidase 41 & 2.19 & $\mathbf{0}$ \\
\hline NM_170672 & RASGRP3 & RAS guanyl releasing protein 3 (calcium and DAG-regulated) & 2.17 & 5.29E-05 \\
\hline NM_001444 & FABP5 & fatty acid binding protein 5 (psoriasis-associated) & 2.16 & $\mathbf{0}$ \\
\hline NM_005953 & MT2A & metallothionein $2 \mathrm{~A}$ & 2.16 & $\mathbf{0}$ \\
\hline NM_001002264 & EPSTI1 & epithelial stromal interaction 1 (breast) & 2.14 & 4.15E-07 \\
\hline NM_198433 & AURKA & aurora kinase $\mathbf{A}$ & 2.11 & 4.07E-06 \\
\hline NM_002800 & PSMB9 & $\begin{array}{l}\text { proteasome (prosome, macropain) subunit, beta type, } 9 \text { (large } \\
\text { multifunctional peptidase } 2 \text { ) }\end{array}$ & 2.10 & $9.80 \mathrm{E}-12$ \\
\hline NM_016816 & OAS1 & 2,5-oligoadenylate synthetase 1,40 & 2.07 & $\mathbf{0}$ \\
\hline
\end{tabular}




\begin{tabular}{|c|c|c|c|c|}
\hline Assignment & Gene name & Definition & FC & p-value \\
\hline NM_145343 & APOL1 & apolipoprotein $\mathrm{L}, 1$ & 2.06 & 3.92E-13 \\
\hline NM_018284 & GBP3 & guanylate binding protein 3 & 2.06 & 2.08E-04 \\
\hline NM_022147 & RTP4 & receptor (chemosensory) transporter protein 4 & 2.06 & 4.17E-05 \\
\hline NM_017414 & USP18 & ubiquitin specific peptidase 18 & 2.06 & $\mathbf{0}$ \\
\hline NM_001547 & IFIT2 & interferon-induced protein with tetratricopeptide repeats 2 & 2.01 & 3.55E-11 \\
\hline NM_014398 & LAMP3 & lysosomal-associated membrane protein 3 & 1.99 & $1.53 \mathrm{E}-11$ \\
\hline NM_005733 & KIF20A & kinesin family member $20 \mathrm{~A}$ & 1.97 & 1.49E-04 \\
\hline NM_001548 & IFIT1 & interferon-induced protein with tetratricopeptide repeats 1 & 1.96 & 0 \\
\hline NM_000798 & DRD5 & dopamine receptor D5 & 1.95 & $1.58 \mathrm{E}-04$ \\
\hline NM_003141 & TRIM21 & tripartite motif-containing 21 & 1.95 & $1.51 \mathrm{E}-10$ \\
\hline NM_006074 & TRIM22 & tripartite motif-containing 22 & 1.93 & $2.80 \mathrm{E}-02$ \\
\hline NM_001031683 & IFIT3 & interferon-induced protein with tetratricopeptide repeats 3 & 1.92 & 2.02E-13 \\
\hline NM_002462 & MX1 & $\begin{array}{l}\text { myxovirus (influenza virus) resistance } 1 \text {, interferon-inducible protein } \\
\text { p78 (mouse) }\end{array}$ & 1.92 & 0 \\
\hline NM_003004 & SECTM1 & secreted and transmembrane 1 & 1.92 & $6.93 \mathrm{E}-09$ \\
\hline NM_000526 & KRT14 & keratin 14 (epidermolysis bullosa simplex, Dowling-Meara, Koebner) & 1.91 & $4.42 \mathrm{E}-10$ \\
\hline NM_172208 & TAPBP & TAP binding protein (tapasin) & 1.91 & $1.35 \mathrm{E}-06$ \\
\hline NM_006417 & IFI44 & interferon-induced protein 44 & 1.89 & 0 \\
\hline NM_004693 & KRT75 & keratin 75 & 1.89 & $3.81 \mathrm{E}-03$ \\
\hline NM_006355 & TRIM38 & tripartite motif-containing 38 & 1.89 & $1.54 \mathrm{E}-08$ \\
\hline NM_006479 & RAD51AP1 & RAD51 associated protein 1 & 1.88 & $1.37 \mathrm{E}-03$ \\
\hline NM_018295 & TMEM140 & transmembrane protein 140 & 1.88 & $1.30 \mathrm{E}-03$ \\
\hline NM_014750 & DLG7 & discs, large homolog 7 (Drosophila) & 1.87 & $2.14 \mathrm{E}-04$ \\
\hline NM_032545 & $\mathrm{CFC} 1$ & cripto, FRL-1, cryptic family 1 & 1.85 & $1.16 \mathrm{E}-02$ \\
\hline NM_006877 & GMPR & guanosine monophosphate reductase & 1.85 & $1.42 \mathrm{E}-05$ \\
\hline NM_020056 & HLA-DQA2 & major histocompatibility complex, class II, DQ alpha 2 & 1.85 & 0 \\
\hline NM_014831 & LBA1 & lupus brain antigen 1 & 1.84 & $8.76 \mathrm{E}-06$ \\
\hline NM_005435 & ARHGEF5 & Rho guanine nucleotide exchange factor (GEF) 5 & 1.83 & $1.12 \mathrm{E}-05$ \\
\hline NM_003521 & HIST1H2BM & histone cluster $1, \mathrm{H} 2 \mathrm{bm}$ & 1.83 & $2.11 \mathrm{E}-08$ \\
\hline XR_017543 & LOC400578 & hypothetical gene supported by BC039169; NM_005557 & 1.83 & 7.48E-08 \\
\hline NM_031458 & PARP9 & poly (ADP-ribose) polymerase family, member 9 & 1.83 & $2.02 \mathrm{E}-13$ \\
\hline NM_178517 & PIGW & phosphatidylinositol glycan anchor biosynthesis, class W & 1.83 & $6.31 \mathrm{E}-03$ \\
\hline ENST00000298566 & BCL2L14 & BCL2-like 14 (apoptosis facilitator) (BCL2L14), transcript variant 3 & 1.82 & $7.96 \mathrm{E}-03$ \\
\hline NM_031966 & CCNB1 & cyclin B1 & 1.82 & $1.24 \mathrm{E}-04$ \\
\hline NM_000433 & NCF2 & neutrophil cytosolic factor 2 & 1.82 & 2.37E-06 \\
\hline NM_006994 & BTN3A3 & butyrophilin, subfamily 3 , member A3 & 1.80 & 5.64E-03 \\
\hline NM_012420 & IFIT5 & interferon-induced protein with tetratricopeptide repeats 5 & 1.80 & $1.20 \mathrm{E}-07$ \\
\hline NM_006101 & NDC80 & NDC80 homolog, kinetochore complex component (S. cerevisiae) & 1.80 & 7.14E-03 \\
\hline NM_003733 & OASL & 2-5-oligoadenylate synthetase-like & 1.80 & 9.85E-09 \\
\hline NM_022872 & IFI6 & interferon, alpha-inducible protein 6 & 1.78 & 0 \\
\hline NM_000625 & NOS2A & nitric oxide synthase 2A (inducible, hepatocytes) & 1.78 & 7.05E-04 \\
\hline NM_002983 & CCL3 & chemokine (C-C motif) ligand 3 & 1.77 & 7.31E-03 \\
\hline NM_017878 & HRASLS2 & HRAS-like suppressor 2 & 1.77 & 7.84E-03 \\
\hline NM_003561 & PLA2G10 & phospholipase A2, group X & 1.77 & $2.12 \mathrm{E}-02$ \\
\hline NM_004159 & PSMB8 & $\begin{array}{l}\text { proteasome (prosome, macropain) subunit, beta type, } 8 \text { (large } \\
\text { multifunctional peptidase } 7 \text { ) }\end{array}$ & 1.77 & $1.30 \mathrm{E}-05$ \\
\hline NM_000593 & TAP1 & transporter 1, ATP-binding cassette, sub-family B (MDR) & 1.77 & $5.59 \mathrm{E}-10$ \\
\hline NM_207315 & LOC 129607 & hypothetical protein LOC129607 & 1.75 & 2.76E-08 \\
\hline NM_032206 & NLRC5 & NLR family, CARD domain containing 5 & 1.75 & $1.47 \mathrm{E}-04$ \\
\hline NM_002129 & HMGB2 & high-mobility group box 2 & 1.74 & $1.58 \mathrm{E}-04$ \\
\hline NM_006850 & IL24 & interleukin 24 & 1.74 & $6.91 \mathrm{E}-06$ \\
\hline NM_000544 & TAP2 & transporter 2, ATP-binding cassette, sub-family B (MDR) & 1.74 & $2.58 \mathrm{E}-05$ \\
\hline NM_005557 & KRT16 & keratin 16 (focal non-epidermolytic palmoplantar keratoderma) & 1.73 & $1.18 \mathrm{E}-03$ \\
\hline
\end{tabular}




\begin{tabular}{|c|c|c|c|c|}
\hline Assignment & Gene name & Definition & FC & p-value \\
\hline NM_022553 & VPS52 & vacuolar protein sorting 52 homolog $(S$. cerevisiae $)$ & 1.73 & $2.23 \mathrm{E}-06$ \\
\hline NM_014783 & ARHGAP11A & Rho GTPase activating protein $11 \mathrm{~A}$ & 1.72 & 4.64E-03 \\
\hline NM_138287 & DTX3L & deltex 3-like (Drosophila) & 1.72 & $3.59 \mathrm{E}-08$ \\
\hline ENST00000326176 & FLJ11286 & hypothetical protein FLJ11286 (FLJ11286), mRNA & 1.72 & $3.43 \mathrm{E}-07$ \\
\hline NM_033109 & PNPT1 & polyribonucleotide nucleotidyltransferase 1 & 1.71 & $3.97 \mathrm{E}-11$ \\
\hline NM_017654 & SAMD9 & sterile alpha motif domain containing 9 & 1.71 & 4.68E-08 \\
\hline NM_001237 & CCNA2 & cyclin A2 & 1.69 & $1.20 \mathrm{E}-04$ \\
\hline NM_000422 & KRT17 & keratin 17 & 1.69 & $2.30 \mathrm{E}-04$ \\
\hline NM_005419 & STAT2 & signal transducer and activator of transcription $2,113 \mathrm{kDa}$ & 1.69 & $1.04 \mathrm{E}-08$ \\
\hline NM_181802 & UBE2C & ubiquitin-conjugating enzyme E2C & 1.69 & $1.25 \mathrm{E}-02$ \\
\hline NM_021066 & HIST1H2AJ & histone cluster $1, \mathrm{H} 2 \mathrm{aj}$ & 1.68 & $2.27 \mathrm{E}-02$ \\
\hline ENST00000369163 & HIST2H3C & histone cluster 2, H3c (HIST2H3C), mRNA & 1.68 & $8.41 \mathrm{E}-08$ \\
\hline NM_004761 & RGL2 & ral guanine nucleotide dissociation stimulator-like 2 & 1.68 & $3.75 \mathrm{E}-02$ \\
\hline NM_138456 & BATF2 & basic leucine zipper transcription factor, ATF-like 2 & 1.67 & 7.24E-04 \\
\hline NM_031299 & CDCA3 & cell division cycle associated 3 & 1.67 & $2.86 \mathrm{E}-03$ \\
\hline NM_024119 & DHX58 & DEXH (Asp-Glu-X-His) box polypeptide 58 & 1.67 & $1.00 \mathrm{E}-05$ \\
\hline NM_001098479 & HLA-F & major histocompatibility complex, class I, F & 1.67 & $2.24 \mathrm{E}-06$ \\
\hline NM_021105 & PLSCR1 & phospholipid scramblase 1 & 1.67 & $1.88 \mathrm{E}-06$ \\
\hline NM_001034841 & LOC 162073 & hypothetical protein LOC 162073 & 1.66 & 2.99E-05 \\
\hline NM_002818 & PSME2 & proteasome (prosome, macropain) activator subunit 2 (PA28 beta) & 1.66 & $3.81 \mathrm{E}-05$ \\
\hline NM_004223 & UBE2L6 & ubiquitin-conjugating enzyme E2L 6 & 1.66 & $1.40 \mathrm{E}-06$ \\
\hline NM_031212 & SLC25A28 & solute carrier family 25 , member 28 & 1.65 & $1.79 \mathrm{E}-03$ \\
\hline NM_001786 & $\mathrm{CDC} 2$ & cell division cycle $2, \mathrm{G} 1$ to $\mathrm{S}$ and $\mathrm{G} 2$ to $\mathrm{M}$ & 1.64 & 4.99E-02 \\
\hline NM_014314 & DDX58 & DEAD (Asp-Glu-Ala-Asp) box polypeptide 58 & 1.64 & $1.24 \mathrm{E}-06$ \\
\hline NM_018950 & HLA-F & major histocompatibility complex, class I, F & 1.64 & 4.03E-06 \\
\hline NM_007047 & BTN3A2 & butyrophilin, subfamily 3 , member A2 & 1.62 & $1.45 \mathrm{E}-05$ \\
\hline NM_014143 & CD274 & CD274 molecule & 1.62 & $6.66 \mathrm{E}-04$ \\
\hline NM_006435 & IFITM2 & interferon induced transmembrane protein $2(1-8 \mathrm{D})$ & 1.62 & $1.85 \mathrm{E}-05$ \\
\hline NM_002346 & LY6E & lymphocyte antigen 6 complex, locus E & 1.62 & $1.42 \mathrm{E}-05$ \\
\hline NM_152649 & MLKL & mixed lineage kinase domain-like & 1.62 & $2.25 \mathrm{E}-03$ \\
\hline NM_024956 & TMEM62 & transmembrane protein 62 & 1.62 & $6.56 \mathrm{E}-06$ \\
\hline NM_016619 & PLAC8 & placenta-specific 8 & 1.61 & $6.42 \mathrm{E}-06$ \\
\hline NM_001040458 & ARTS-1 & type 1 tumor necrosis factor receptor shedding aminopeptidase regulator & 1.60 & 4.87E-02 \\
\hline NM_003529 & HIST1H3A & histone cluster $1, \mathrm{H} 3 \mathrm{a}$ & 1.60 & $1.67 \mathrm{E}-04$ \\
\hline NM_003534 & HIST1H3G & histone cluster $1, \mathrm{H} 3 \mathrm{~g}$ & 1.60 & $3.23 \mathrm{E}-02$ \\
\hline NM_002166 & ID2 & inhibitor of DNA binding 2, dominant negative helix-loop-helix protein & 1.60 & 3.39E-02 \\
\hline NM_005480 & TROAP & trophinin associated protein (tastin) & 1.60 & 4.21E-03 \\
\hline NM_017912 & HERC6 & hect domain and RLD 6 & 1.59 & $8.02 \mathrm{E}-05$ \\
\hline NM_002659 & PLAUR & plasminogen activator, urokinase receptor & 1.59 & 9.29E-06 \\
\hline NM_001827 & CKS2 & CDC28 protein kinase regulatory subunit 2 & 1.58 & 2.18E-05 \\
\hline NM_004496 & FOXA1 & forkhead box A1 & 1.58 & $1.18 \mathrm{E}-03$ \\
\hline NM_002214 & ITGB8 & integrin, beta 8 & 1.58 & $4.16 \mathrm{E}-02$ \\
\hline NM_006342 & TACC3 & transforming, acidic coiled-coil containing protein 3 & 1.58 & $4.46 \mathrm{E}-02$ \\
\hline NM_003246 & THBS1 & thrombospondin 1 & 1.58 & 3.89E-04 \\
\hline NM_052864 & TIFA & TRAF-interacting protein with a forkhead-associated domain & 1.58 & $1.95 \mathrm{E}-02$ \\
\hline NM_003513 & HIST1H2AB & histone cluster $1, \mathrm{H} 2 \mathrm{ab}$ & 1.57 & $2.86 \mathrm{E}-03$ \\
\hline NM_005516 & HLA-E & major histocompatibility complex, class I, E & 1.57 & $1.08 \mathrm{E}-06$ \\
\hline NM_032844 & MASTL & microtubule associated serine & 1.57 & $2.31 \mathrm{E}-05$ \\
\hline NM_005982 & SIX1 & SIX homeobox 1 & 1.57 & $1.59 \mathrm{E}-02$ \\
\hline NM_198956 & SP8 & Sp8 transcription factor & 1.57 & $1.24 \mathrm{E}-04$ \\
\hline NM_006461 & SPAG5 & sperm associated antigen 5 & 1.57 & $2.78 \mathrm{E}-02$ \\
\hline NM_004217 & AURKB & aurora kinase B & 1.56 & 4.63E-04 \\
\hline
\end{tabular}




\begin{tabular}{|c|c|c|c|c|}
\hline Assignment & Gene name & Definition & FC & p-value \\
\hline NM_001251 & CD68 & CD68 molecule & 1.56 & $2.49 \mathrm{E}-06$ \\
\hline NM_002178 & IGFBP6 & insulin-like growth factor binding protein 6 & 1.56 & $2.73 \mathrm{E}-07$ \\
\hline NM_005567 & LGALS3BP & lectin, galactoside-binding, soluble, 3 binding protein & 1.56 & $2.26 \mathrm{E}-06$ \\
\hline NM_032789 & PARP10 & poly (ADP-ribose) polymerase family, member 10 & 1.56 & $1.30 \mathrm{E}-03$ \\
\hline NM_001274 & CHEK1 & CHK1 checkpoint homolog (S. pombe) & 1.55 & $1.74 \mathrm{E}-02$ \\
\hline NM_001955 & EDN1 & endothelin 1 & 1.55 & $4.80 \mathrm{E}-02$ \\
\hline NM_002116 & HLA-A & major histocompatibility complex, class I, A & 1.55 & $7.78 \mathrm{E}-07$ \\
\hline NM_006845 & $\mathrm{KIF} 2 \mathrm{C}$ & kinesin family member $2 \mathrm{C}$ & 1.55 & $6.44 \mathrm{E}-03$ \\
\hline NM_002468 & MYD88 & myeloid differentiation primary response gene (88) & 1.55 & $8.02 \mathrm{E}-05$ \\
\hline NM_003981 & PRC1 & protein regulator of cytokinesis 1 & 1.55 & $6.24 \mathrm{E}-04$ \\
\hline NM_001040874 & HIST2H2AA4 & histone cluster $2, \mathrm{H} 2 \mathrm{aa} 4$ & 1.54 & $2.55 \mathrm{E}-05$ \\
\hline NM_003517 & $\mathrm{HIST} 2 \mathrm{H} 2 \mathrm{AC}$ & histone cluster $2, \mathrm{H} 2 \mathrm{ac}$ & 1.54 & $1.59 \mathrm{E}-06$ \\
\hline NM_021059 & HIST2H3C & histone cluster $2, \mathrm{H} 3 \mathrm{c}$ & 1.54 & $1.49 \mathrm{E}-04$ \\
\hline ВC032140 & HMGN2 & high-mobility group nucleosomal binding domain 2 & 1.54 & $6.99 \mathrm{E}-06$ \\
\hline NM_021013 & KRT34 & keratin 34 & 1.54 & 4.37E-05 \\
\hline NM_004848 & C1orf38 & chromosome 1 open reading frame 38 & 1.53 & $8.02 \mathrm{E}-05$ \\
\hline NM_152562 & CDCA2 & cell division cycle associated 2 & 1.53 & $2.16 \mathrm{E}-02$ \\
\hline NM_012291 & ESPL1 & extra spindle pole bodies homolog 1 (S. cerevisiae) & 1.53 & $5.04 \mathrm{E}-02$ \\
\hline NM_202002 & FOXM1 & forkhead box M1 & 1.53 & $4.00 \mathrm{E}-03$ \\
\hline NM_002263 & $\mathrm{KIFC1}$ & kinesin family member $\mathrm{C} 1$ & 1.53 & $1.96 \mathrm{E}-04$ \\
\hline NM_033049 & MUC13 & mucin 13 , cell surface associated & 1.53 & $7.56 \mathrm{E}-05$ \\
\hline NM_002485 & NBN & nibrin & 1.53 & $1.21 \mathrm{E}-02$ \\
\hline NM_024515 & WDR25 & WD repeat domain 25 & 1.53 & $3.47 \mathrm{E}-02$ \\
\hline NM_030641 & APOL6 & apolipoprotein L, 6 & 1.52 & $1.12 \mathrm{E}-02$ \\
\hline NM_000775 & CYP2J2 & cytochrome P450, family 2 , subfamily $\mathrm{J}$, polypeptide 2 & 1.52 & $1.29 \mathrm{E}-02$ \\
\hline ENST00000373451 & KIAA0082 & KIAA0082 (KIAA0082), mRNA & 1.52 & $2.41 \mathrm{E}-04$ \\
\hline NM_018438 & FBXO6 & F-box protein 6 & 1.51 & $3.42 \mathrm{E}-03$ \\
\hline AK131222 & HSH2D & hematopoietic $\mathrm{SH} 2$ domain containing & 1.51 & 4.99E-05 \\
\hline NM_000265 & NCF1 & neutrophil cytosolic factor 1 & 1.51 & $7.96 \mathrm{E}-03$ \\
\hline NM_152905 & NEDD1 & neural precursor cell expressed, developmentally down-regulated 1 & 1.51 & $5.59 \mathrm{E}-04$ \\
\hline NR_002961 & SNORA22 & small nucleolar RNA, H & 1.51 & $6.63 \mathrm{E}-05$ \\
\hline NM_002105 & H2AFX & $\mathrm{H} 2 \mathrm{~A}$ histone family, member $\mathrm{X}$ & 1.49 & $1.50 \mathrm{E}-03$ \\
\hline NM_003528 & $\mathrm{HIST} 2 \mathrm{H} 2 \mathrm{BE}$ & histone cluster 2, H2be & 1.49 & $5.03 \mathrm{E}-03$ \\
\hline NM_002116 & HLA-A & major histocompatibility complex, class I, A & 1.49 & $5.49 \mathrm{E}-03$ \\
\hline NM_002201 & ISG20 & interferon stimulated exonuclease gene $20 \mathrm{kDa}$ & 1.49 & $2.26 \mathrm{E}-03$ \\
\hline NM_004776 & B4GALT5 & UDP-Gal:betaGlcNAc beta 1,4- galactosyltransferase, polypeptide 5 & 1.48 & $1.43 \mathrm{E}-04$ \\
\hline NM_000235 & LIPA & lipase A, lysosomal acid, cholesterol esterase (Wolman disease) & 1.48 & $1.84 \mathrm{E}-03$ \\
\hline NM_003827 & NAPA & N-ethylmaleimide-sensitive factor attachment protein, alpha & 1.48 & 8.53E-04 \\
\hline NM_001037335 & PRIC285 & peroxisomal proliferator-activated receptor A interacting complex 285 & 1.48 & $1.16 \mathrm{E}-03$ \\
\hline uc002tfz.1 & RGPD5 & RANBP2-like and GRIP domain containing 5 & 1.48 & $3.36 \mathrm{E}-02$ \\
\hline NM_018009 & TAPBPL & TAP binding protein-like & 1.48 & $2.10 \mathrm{E}-03$ \\
\hline NM_020453 & ATP10D & ATPase, Class V, type 10D & 1.47 & $3.12 \mathrm{E}-02$ \\
\hline BC126339 & H2BFS & $\mathrm{H} 2 \mathrm{~B}$ histone family, member $\mathrm{S}$ & 1.47 & $1.28 \mathrm{E}-03$ \\
\hline NM_002117 & HLA-C & major histocompatibility complex, class I, C & 1.47 & $3.50 \mathrm{E}-04$ \\
\hline NM_005532 & IFI27 & interferon, alpha-inducible protein 27 & 1.47 & 4.11E-04 \\
\hline NM_021034 & IFITM3 & interferon induced transmembrane protein $3(1-8 \mathrm{U})$ & 1.47 & $9.13 \mathrm{E}-05$ \\
\hline NM_005573 & LMNB1 & lamin B1 & 1.47 & $3.40 \mathrm{E}-03$ \\
\hline AF193059 & LOC26010 & viral DNA polymerase-transactivated protein 6 & 1.47 & $1.83 \mathrm{E}-04$ \\
\hline NM_016457 & PRKD2 & protein kinase D2 & 1.47 & $2.08 \mathrm{E}-04$ \\
\hline ENST00000389055 & PYROXD1 & hypothetical protein FLJ22028 (FLJ22028), mRNA & 1.47 & 4.64E-03 \\
\hline NM_007048 & BTN3A1 & butyrophilin, subfamily 3 , member A1 & 1.46 & $2.06 \mathrm{E}-02$ \\
\hline $\mathrm{BC} 033660$ & DBF4B & DBF4 homolog B (S. cerevisiae) & 1.46 & $3.55 \mathrm{E}-02$ \\
\hline
\end{tabular}




\begin{tabular}{|c|c|c|c|c|}
\hline Assignment & Gene name & Definition & $\mathbf{F C}$ & p-value \\
\hline NM_016095 & GINS2 & GINS complex subunit 2 (Psf2 homolog) & 1.46 & $3.69 \mathrm{E}-02$ \\
\hline NM_024736 & GSDMDC1 & gasdermin domain containing 1 & 1.46 & $1.30 \mathrm{E}-02$ \\
\hline NM_006187 & OAS3 & 2-5-oligoadenylate synthetase $3,100 \mathrm{kDa}$ & 1.46 & 2.39E-05 \\
\hline NM_017554 & PARP14 & poly (ADP-ribose) polymerase family, member 14 & 1.46 & $3.35 \mathrm{E}-05$ \\
\hline NM_007315 & STAT1 & signal transducer and activator of transcription $1,91 \mathrm{kDa}$ & 1.46 & $4.05 \mathrm{E}-05$ \\
\hline NM_203401 & STMN1 & stathmin 1 & 1.46 & 4.61E-02 \\
\hline ENST00000331615 & TMEM106A & transmembrane protein 106A (TMEM106A), mRNA & 1.46 & $2.40 \mathrm{E}-02$ \\
\hline NM_005192 & CDKN3 & cyclin-dependent kinase inhibitor 3 & 1.45 & $3.20 \mathrm{E}-02$ \\
\hline NM_001012967 & FLJ31033 & hypothetical protein FLJ31033 & 1.45 & $2.71 \mathrm{E}-03$ \\
\hline AK023116 & LOC93349 & hypothetical protein $\mathrm{BC} 004921$ & 1.45 & $3.69 \mathrm{E}-02$ \\
\hline NM_022346 & NCAPG & non-SMC condensin I complex, subunit G & 1.45 & $1.58 \mathrm{E}-04$ \\
\hline NM_004346 & CASP3 & caspase 3 , apoptosis-related cysteine peptidase & 1.44 & $1.65 \mathrm{E}-02$ \\
\hline NM_018101 & CDCA8 & cell division cycle associated 8 & 1.44 & 2.39E-02 \\
\hline NM_002006 & FGF2 & fibroblast growth factor 2 (basic) & 1.44 & $5.86 \mathrm{E}-04$ \\
\hline NM_003530 & HIST1H3D & histone cluster $1, \mathrm{H} 3 \mathrm{~d}$ & 1.44 & $1.24 \mathrm{E}-03$ \\
\hline NM_175065 & HIST2H2AB & histone cluster $2, \mathrm{H} 2 \mathrm{ab}$ & 1.44 & $1.59 \mathrm{E}-04$ \\
\hline NM_005346 & HSPA1B & heat shock $70 \mathrm{kDa}$ protein $1 \mathrm{~B}$ & 1.44 & 4.11E-04 \\
\hline NM_016359 & NUSAP1 & nucleolar and spindle associated protein 1 & 1.44 & $2.59 \mathrm{E}-03$ \\
\hline NM_176783 & PSME1 & proteasome (prosome, macropain) activator subunit 1 (PA28 alpha) & 1.44 & $1.62 \mathrm{E}-03$ \\
\hline NM_031229 & RBCK1 & RanBP-type and C3HC4-type zinc finger containing 1 & 1.44 & $6.34 \mathrm{E}-03$ \\
\hline NM_014501 & UBE2S & ubiquitin-conjugating enzyme E2S & 1.44 & $1.13 \mathrm{E}-02$ \\
\hline NM_138441 & C6orf150 & chromosome 6 open reading frame 150 & 1.43 & $5.44 \mathrm{E}-03$ \\
\hline NM_033133 & CNP & 2,3-cyclic nucleotide 3 phosphodiesterase & 1.43 & $9.38 \mathrm{E}-03$ \\
\hline NM_012100 & DNPEP & aspartyl aminopeptidase & 1.43 & $2.69 \mathrm{E}-03$ \\
\hline AF087992 & EIF5A & eukaryotic translation initiation factor $5 \mathrm{~A}$ & 1.43 & $1.56 \mathrm{E}-06$ \\
\hline NM_003080 & SMPD2 & sphingomyelin phosphodiesterase 2 , neutral membrane & 1.43 & $8.12 \mathrm{E}-03$ \\
\hline NR_002588 & SNORA4 & small nucleolar RNA, H & 1.43 & $2.33 \mathrm{E}-02$ \\
\hline NM_001001522 & TAGLN & transgelin & 1.43 & 7.14E-03 \\
\hline NM_004457 & ACSL3 & acyl-CoA synthetase long-chain family member 3 & 1.42 & $3.62 \mathrm{E}-02$ \\
\hline NM_022168 & IFIH1 & interferon induced with helicase $\mathrm{C}$ domain 1 & 1.42 & $1.45 \mathrm{E}-04$ \\
\hline NM_005101 & ISG15 & ISG15 ubiquitin-like modifier & 1.42 & $1.79 \mathrm{E}-04$ \\
\hline NM_020189 & ENY2 & enhancer of yellow 2 homolog (Drosophila) & 1.41 & $3.39 \mathrm{E}-02$ \\
\hline NM_001034194 & EXOSC9 & exosome component 9 & 1.41 & $1.80 \mathrm{E}-03$ \\
\hline NM_033055 & HIAT1 & hippocampus abundant transcript 1 & 1.41 & 8.92E-03 \\
\hline NM_003537 & HIST1H3B & histone cluster $1, \mathrm{H} 3 \mathrm{~b}$ & 1.41 & 2.19E-02 \\
\hline NM_173086 & KRT6C & keratin $6 \mathrm{C}$ & 1.41 & $3.78 \mathrm{E}-02$ \\
\hline NM_031419 & NFKBIZ & $\begin{array}{l}\text { nuclear factor of kappa light polypeptide gene enhancer in B-cells } \\
\text { inhibitor, zeta }\end{array}$ & 1.41 & $2.05 \mathrm{E}-02$ \\
\hline NM_007173 & PRSS23 & protease, serine, 23 & 1.41 & $3.40 \mathrm{E}-03$ \\
\hline NM_004219 & PTTG1 & pituitary tumor-transforming 1 & 1.41 & $3.15 \mathrm{E}-02$ \\
\hline ENST00000330794 & TMEM173 & transmembrane protein 173 (TMEM173), mRNA & 1.41 & $1.91 \mathrm{E}-02$ \\
\hline NM_001004196 & CD200 & CD200 molecule & 1.40 & $2.48 \mathrm{E}-02$ \\
\hline NM_004417 & DUSP1 & dual specificity phosphatase 1 & 1.40 & $5.84 \mathrm{E}-03$ \\
\hline NM_030919 & FAM83D & family with sequence similarity 83 , member D & 1.40 & $2.43 \mathrm{E}-02$ \\
\hline NM_020238 & INCENP & inner centromere protein antigens 135 & 1.40 & $4.43 \mathrm{E}-02$ \\
\hline XM_929774 & LOC646817 & SET nuclear oncogene pseudogene & 1.40 & 7.81E-03 \\
\hline NM_014321 & ORC6L & origin recognition complex, subunit 6 like (yeast) & 1.40 & $2.05 \mathrm{E}-02$ \\
\hline NM_198490 & RAB43 & RAB43, member RAS oncogene family & 1.40 & $1.04 \mathrm{E}-02$ \\
\hline NM_144975 & SLFN5 & schlafen family member 5 & 1.40 & $8.41 \mathrm{E}-03$ \\
\hline ENST00000263384 & FAM32A & family with sequence similarity 32 , member A (FAM32A), mRNA & 1.39 & 4.43E-02 \\
\hline NM_001001555 & GRB10 & growth factor receptor-bound protein 10 & 1.39 & $1.06 \mathrm{E}-03$ \\
\hline NM_003524 & HIST1H2BH & histone cluster $1, \mathrm{H} 2 \mathrm{bh}$ & 1.39 & $1.64 \mathrm{E}-02$ \\
\hline
\end{tabular}




\begin{tabular}{|c|c|c|c|c|}
\hline Assignment & Gene name & Definition & FC & p-value \\
\hline NM_006041 & HS3ST3B1 & heparan sulfate (glucosamine) 3-O-sulfotransferase 3B1 & 1.39 & $4.61 \mathrm{E}-02$ \\
\hline NM_006332 & IFI30 & interferon, gamma-inducible protein 30 & 1.39 & $2.05 \mathrm{E}-02$ \\
\hline NM_002198 & IRF1 & interferon regulatory factor 1 & 1.39 & $1.02 \mathrm{E}-02$ \\
\hline NM_015907 & LAP3 & leucine aminopeptidase 3 & 1.39 & $3.55 \mathrm{E}-02$ \\
\hline NM_021127 & PMAIP1 & phorbol-12-myristate-13-acetate-induced protein 1 & 1.39 & $3.78 \mathrm{E}-03$ \\
\hline ENST00000305363 & TMPRSS11E & transmembrane protease, serine 11E (TMPRSS11E), mRNA & 1.39 & $3.31 \mathrm{E}-03$ \\
\hline NM_001079539 & XBP1 & X-box binding protein 1 & 1.39 & $2.57 \mathrm{E}-03$ \\
\hline NM_030882 & APOL2 & apolipoprotein L, 2 & 1.39 & $2.31 \mathrm{E}-05$ \\
\hline NM_212482 & FN1 & fibronectin 1 & 1.39 & 4.41E-02 \\
\hline NM_005322 & HIST1H1B & histone cluster $1, \mathrm{H} 1 \mathrm{~b}$ & 1.39 & $1.49 \mathrm{E}-04$ \\
\hline NM_002451 & MTAP & methylthioadenosine phosphorylase & 1.39 & $2.86 \mathrm{E}-03$ \\
\hline NR_002754 & RNU5E & RNA, U5E small nuclear & 1.39 & $1.50 \mathrm{E}-03$ \\
\hline NM_025075 & THOC7 & THO complex 7 homolog (Drosophila) & 1.39 & 1.17E-02 \\
\hline NM_020119 & ZC3HAV1 & zinc finger CCCH-type, antiviral 1 & 1.39 & 7.44E-04 \\
\hline NM_022488 & ATG3 & ATG3 autophagy related 3 homolog (S. cerevisiae) & 1.38 & $1.70 \mathrm{E}-02$ \\
\hline NM_174983 & C19orf28 & chromosome 19 open reading frame 28 & 1.38 & $3.85 \mathrm{E}-02$ \\
\hline NM_002388 & MCM3 & minichromosome maintenance complex component 3 & 1.38 & 4.42E-02 \\
\hline NM_022061 & MRPL17 & mitochondrial ribosomal protein L17 & 1.38 & $2.73 \mathrm{E}-02$ \\
\hline ENST00000314842 & RPL41 & ribosomal protein L41 (RPL41), transcript variant 2, mRNA & 1.38 & $2.68 \mathrm{E}-02$ \\
\hline NM_033518 & SLC38A5 & solute carrier family 38 , member 5 & 1.38 & $3.14 \mathrm{E}-02$ \\
\hline NM_001080391 & SP100 & SP100 nuclear antigen & 1.38 & $9.88 \mathrm{E}-03$ \\
\hline NM_007109 & TCF19 & transcription factor $19(\mathrm{SC} 1)$ & 1.38 & 4.45E-04 \\
\hline NM_014290 & TDRD7 & tudor domain containing 7 & 1.38 & $3.85 \mathrm{E}-02$ \\
\hline NM_033034 & TRIM5 & tripartite motif-containing 5 & 1.38 & $6.67 \mathrm{E}-03$ \\
\hline NM_033286 & C15orf23 & chromosome 15 open reading frame 23 & 1.37 & 4.99E-02 \\
\hline NM_012193 & FZD4 & frizzled homolog 4 (Drosophila) & 1.37 & $2.90 \mathrm{E}-02$ \\
\hline NM_022750 & PARP12 & poly (ADP-ribose) polymerase family, member 12 & 1.37 & $3.82 \mathrm{E}-03$ \\
\hline NM_006915 & RP2 & retinitis pigmentosa 2 (X-linked recessive) & 1.37 & 4.99E-02 \\
\hline NM_003132 & SRM & spermidine synthase & 1.37 & 7.93E-03 \\
\hline NM_012342 & BAMBI & BMP and activin membrane-bound inhibitor homolog (Xenopus laevis) & 1.36 & $2.42 \mathrm{E}-02$ \\
\hline NM_021018 & HIST1H3F & histone cluster $1, \mathrm{H} 3 \mathrm{f}$ & 1.36 & $1.13 \mathrm{E}-02$ \\
\hline NM_005514 & HLA-B & major histocompatibility complex, class I, B & 1.36 & $2.48 \mathrm{E}-04$ \\
\hline NM_002357 & MXD1 & MAX dimerization protein 1 & 1.36 & $1.12 \mathrm{E}-02$ \\
\hline NM_013290 & PSMC3IP & PSMC3 interacting protein & 1.36 & $3.96 \mathrm{E}-02$ \\
\hline NM_001007230 & SPOP & speckle-type POZ protein & 1.36 & $7.14 \mathrm{E}-03$ \\
\hline NM_024092 & TMEM109 & transmembrane protein 109 & 1.36 & $5.19 \mathrm{E}-03$ \\
\hline NM_003541 & HIST1H4K & histone cluster $1, \mathrm{H} 4 \mathrm{k}$ & 1.35 & $1.17 \mathrm{E}-02$ \\
\hline ВС020891 & HLA-G & HLA-G histocompatibility antigen, class I, G & 1.35 & $1.03 \mathrm{E}-02$ \\
\hline NM_020529 & NFKBIA & $\begin{array}{l}\text { nuclear factor of kappa light polypeptide gene enhancer in B-cells } \\
\text { inhibitor, alpha }\end{array}$ & 1.35 & 4.39E-03 \\
\hline NM_001657 & AREG & amphiregulin (schwannoma-derived growth factor) & 1.34 & $3.54 \mathrm{E}-02$ \\
\hline NM_015161 & ARL6IP1 & ADP-ribosylation factor-like 6 interacting protein 1 & 1.34 & $5.40 \mathrm{E}-03$ \\
\hline NM_016289 & CAB39 & calcium binding protein 39 & 1.34 & $4.36 \mathrm{E}-03$ \\
\hline NM_001826 & CKS1B & CDC28 protein kinase regulatory subunit $1 \mathrm{~B}$ & 1.34 & $3.69 \mathrm{E}-02$ \\
\hline NM_015634 & KIAA1279 & KIAA1279 & 1.34 & $1.18 \mathrm{E}-02$ \\
\hline NM_006739 & MCM5 & minichromosome maintenance complex component 5 & 1.34 & $2.36 \mathrm{E}-02$ \\
\hline NM_003542 & HIST1H4C & histone cluster $1, \mathrm{H} 4 \mathrm{c}$ & 1.33 & $1.14 \mathrm{E}-02$ \\
\hline NM_002228 & JUN & jun oncogene & 1.33 & $3.14 \mathrm{E}-03$ \\
\hline XR_015269 & HIST2H2BE & histone cluster $2, \mathrm{H} 2 \mathrm{be}$ & 1.33 & $2.82 \mathrm{E}-02$ \\
\hline NM_015474 & SAMHD1 & SAM domain and HD domain 1 & 1.33 & $4.56 \mathrm{E}-02$ \\
\hline NM_001307 & CLDN7 & claudin 7 & 1.32 & 4.49E-02 \\
\hline NM_172373 & ELF1 & E74-like factor 1 (ets domain transcription factor) & 1.32 & 4.47E-02 \\
\hline
\end{tabular}




\begin{tabular}{|c|c|c|c|c|}
\hline Assignment & Gene name & Definition & FC & p-value \\
\hline NM_018088 & FAM90A1 & family with sequence similarity 90, member $\mathrm{A} 1$ & 1.32 & $1.17 \mathrm{E}-02$ \\
\hline NM_020150 & SAR1A & SAR1 gene homolog A (S. cerevisiae) & 1.32 & $3.39 \mathrm{E}-02$ \\
\hline NM_024546 & C13orf7 & chromosome 13 open reading frame 7 & 1.31 & 4.43E-02 \\
\hline NM_020409 & MRPL47 & mitochondrial ribosomal protein L47 & 1.31 & 7.06E-03 \\
\hline NM_007346 & OGFR & opioid growth factor receptor & 1.31 & $4.86 \mathrm{E}-03$ \\
\hline NM_003190 & TAPBP & TAP binding protein (tapasin) & 1.31 & $1.29 \mathrm{E}-02$ \\
\hline NM_006088 & TUBB2C & tubulin, beta $2 \mathrm{C}$ & 1.31 & 3.47E-02 \\
\hline NM_001085411 & C5orf33 & chromosome 5 open reading frame 33 & 1.30 & $1.86 \mathrm{E}-02$ \\
\hline XM_001132216 & LOC644589 & similar to translocase of the inner mitochondrial membrane 14 isoform a & 1.30 & $9.48 \mathrm{E}-04$ \\
\hline NM_052886 & MAL2 & mal, T-cell differentiation protein 2 & 1.30 & $1.04 \mathrm{E}-02$ \\
\hline NM_020963 & MOV10 & Mov10, Moloney leukemia virus 10 , homolog (mouse) & 1.30 & 3.69E-02 \\
\hline NM_004289 & NFE2L3 & nuclear factor (erythroid-derived 2)-like 3 & 1.30 & $1.63 \mathrm{E}-02$ \\
\hline NM_002823 & PTMA & prothymosin, alpha (gene sequence 28 ) & 1.30 & $6.96 \mathrm{E}-03$ \\
\hline NM_182965 & SPHK1 & sphingosine kinase 1 & 1.30 & 3.20E-02 \\
\hline NM_004335 & BST2 & bone marrow stromal cell antigen 2 & 1.29 & $1.70 \mathrm{E}-02$ \\
\hline NM_002467 & MYC & v-myc myelocytomatosis viral oncogene homolog (avian) & 1.29 & 2.52E-02 \\
\hline NM_001042616 & PIGY & phosphatidylinositol glycan anchor biosynthesis, class $\mathrm{Y}$ & 1.29 & 4.66E-02 \\
\hline NM_130900 & RAET1L & retinoic acid early transcript $1 \mathrm{~L}$ & 1.29 & $2.80 \mathrm{E}-02$ \\
\hline NM_000043 & FAS & Fas (TNF receptor superfamily, member 6) & 1.28 & 4.29E-02 \\
\hline NM_005324 & H3F3B & H3 histone, family 3B (H3.3B) & 1.28 & 4.45E-02 \\
\hline NM_003533 & HIST1H3I & histone cluster $1, \mathrm{H} 3 \mathrm{i}$ & 1.28 & 7.78E-03 \\
\hline NM_001012333 & MDK & midkine (neurite growth-promoting factor 2) & 1.27 & 4.96E-02 \\
\hline NM_002759 & EIF2AK2 & eukaryotic translation initiation factor 2-alpha kinase 2 & 1.27 & 2.10E-02 \\
\hline NM_005321 & HIST1H1E & histone cluster $1, \mathrm{H} 1 \mathrm{e}$ & 1.27 & $1.25 \mathrm{E}-02$ \\
\hline NR_002564 & SNORD26 & small nucleolar RNA, C & 1.26 & $1.03 \mathrm{E}-02$ \\
\hline NR_002559 & SNORD29 & small nucleolar RNA, C & 1.26 & 2.02E-02 \\
\hline NM_004640 & BAT1 & HLA-B associated transcript 1 & 1.25 & 2.16E-02 \\
\hline NM_007317 & KIF22 & kinesin family member 22 & 1.24 & 2.30E-06 \\
\hline ENST00000336176 & TMEM106B & transmembrane protein 106B (TMEM106B), mRNA & 1.23 & 2.43E-02 \\
\hline NM_001083538 & POTE2 & protein expressed in prostate, ovary, testis, and placenta 2 & 1.22 & 4.63E-02 \\
\hline NM_002116 & HLA-A & major histocompatibility complex, class I, A & 1.21 & $3.61 \mathrm{E}-02$ \\
\hline XR_018749 & KRT18 & keratin 18 & 1.21 & $1.08 \mathrm{E}-02$ \\
\hline NM_032026 & TATDN1 & TatD DNase domain containing 1 & 1.21 & $1.06 \mathrm{E}-04$ \\
\hline
\end{tabular}


Table S5. Oligonucleotides.

\begin{tabular}{|c|c|c|c|}
\hline \multicolumn{2}{|c|}{ Cloning } & \multirow[b]{2}{*}{ Sequence } & \multirow[b]{2}{*}{ Reference } \\
\hline Name & (RS)-Gene & & \\
\hline $438-\mathrm{S} 1$ & $($ BamHI)-5'lnt $A$ & CGCGGATCCGGAATCGCGCACACTTTC & This work \\
\hline $438-\mathrm{S} 2$ & $(S t u \mathrm{I})-5^{\prime} \ln t A$ & AAAAGGCCTTCTTCACTCGTTTTCCTTC & This work \\
\hline $438-\mathrm{S} 3$ & $(S t u \mathrm{I})-3$ 'lnt $A$ & AAAAGGCCTAAGAAAAAGCCGTCCTACAGA & This work \\
\hline $438-\mathrm{S} 4$ & (EcoRI)-3'lntA & CCGGAATTCTATGCAAAAGAGCACGATGCG & This work \\
\hline oHB1 & $(E c o \mathrm{RI})-\ln t A$ & CGGAATTCATGGGAGAGGATGAAGGTGAAC & This work \\
\hline oHB2 & $(X h o \mathrm{I})-\ln t A$ & CCGCTCGAGTTTTTGACTATCCAATAATTC & This work \\
\hline oHB3 & $(\operatorname{SacI})-\ln t A$ & ACGAGCTCTGAAAGAAGGGAAACGAGTG & This work \\
\hline oHB4 & $\operatorname{lnt} A$ & AGTAACCATCGATTTGCTG & This work \\
\hline oHB5 & $(S p h 1)-V 5$ & ACATGCATGCTTAACCGGTACGCGTAGAATC & This work \\
\hline oDB1 & $(E a g I)-5 ' h l y$ & GAGTCACGGCCGATAAAGCAAGCATATAATA & $(41)$ \\
\hline oDB2 & 5 'hly & GGGTTTCACTCTCCTTCTACA & $(41)$ \\
\hline oAL17 & $5 ' h l y-\ln t A$ & $\begin{array}{l}\text { GTTAAAAAATGTAGAAGGAGAGTGAAACCCATG } \\
\text { aagaagttagttgcttggtt }\end{array}$ & This work \\
\hline oAL18 & $($ SalI $)-\ln t A$ & GTCGACTTACTGCAGTTTTTGACTATCCAATAATTCGTA & This work \\
\hline oVJ1 & $($ BamHI)-lntA & AAAGGATCCATGGGAGAGGATGAAGGTGAAC & This work \\
\hline oVJ2 & $(X h o \mathrm{I})-\ln t A$ & TCCCTCGAGTCATTTTTGACTATCCAATAATTCGTAGCC & This work \\
\hline oGL1 & (FseI)-BAHD1 & ATGCGGCCGGCCCATGACACACACTCGGAGAAAG & This work \\
\hline oGL2 & $(A s c \mathrm{I})-B A H D 1$ & AGGCGCGCCCTACTGGGGGTTCTTAAGGA & This work \\
\hline \multicolumn{4}{|c|}{ qRT-PCR on cDNA } \\
\hline Name & Gene & Sequence & Reference \\
\hline gyrA-RT1 & gyrA & GCGATGAGTGTAATTGTTG & (39) \\
\hline gyrA-RT2 & gyrA & ATCAGAAGTCATACCTAAGTC & (39) \\
\hline hly-RT1 & hly & GCTTGAATGTAAACTTCGG & This work \\
\hline hly-RT2 & hly & GCAACTGCTCTTTAGTAAC & This work \\
\hline inlA-RT1 & inlA & ACACGGTCTCACAAACAG & (39) \\
\hline inlA-RT2 & inlA & TCAAGTATTCCACTCCATCG & (39) \\
\hline 438-RT1 & $\ln t A$ & GGAGAGGATGAAGGTGAAC & This work \\
\hline 438-RT2 & $\ln t A$ & TCAAGGCTAAATCTTTGGTTG & This work \\
\hline 16S-RT1 & $16 S r R N A$ & CTCGTGTCGTGAGATGTTGG & $(20)$ \\
\hline 16S-RT2 & $16 S r R N A$ & CGTGTGTAGCCCAGGTCATA & $(20)$ \\
\hline 2845-RT1 & $\operatorname{lmo} 2845$ & GGTGTAGGAACTGCCATCGGACC & $(20)$ \\
\hline 2845-RT2 & $\operatorname{lmo} 2845$ & АСTGCGCGCCAACCATTTGTAGC & $(20)$ \\
\hline
\end{tabular}

\begin{tabular}{lllr}
\hline \multicolumn{2}{c}{ qRT-PCR on ChIP samples } & Reference \\
\hline Name & Gene & Sequence & $(6)$ \\
\hline IGF2-P3-b-F & $I G F 2$ & AAATTTGGGCATtGTTCCCGGCTC & $(6)$ \\
IGF2-P3-b-R & $I G F 2$ & TGTGTTTGGGCAACGCTAGAGAGA & $(6)$ \\
CD44-CpG-F & $C D 44$ & TATTTACAGCCTCAGCAGAGCACG & \\
\hline
\end{tabular}




\begin{tabular}{|c|c|c|c|}
\hline CD44-CpG-R & CD44 & AAACAGTGACCTAAGACGGAGGGA & (6) \\
\hline IFIT3-TS-F & IFIT3 & AAAGCACAGACCTAACAGCACCCT & $(30)$ \\
\hline IFIT3-TS-R & IFIT3 & CATGATGGCTGTTTCCCTGCAGTT & $(30)$ \\
\hline IFITM1-e1-R & IFITM1 & AAGGTCCACCGTGATCAACATCCA & This work \\
\hline IFITM1-e1-F & IFITM1 & AGTAGGCGAATGCTATGAAGCCCA & This work \\
\hline \multicolumn{4}{|c|}{ BAHD1 KO mice - PCR validation of ES clones } \\
\hline Name & PCR product & Sequence & Reference \\
\hline Ef1 & 5' external & TTATAGGCGCGCCCAGAATTGACAAAAGTCAGACCTGG & This work \\
\hline Nr1 & $(4.9 \mathrm{~kb})$ & GCGGCCGGAGAACCTGCGTGCAATC & This work \\
\hline \multicolumn{4}{|c|}{ BAHD1 KO mice - external-probe synthesis } \\
\hline Name & & Sequence & Reference \\
\hline probe2-F & & GGTCTTACGTCCAGTGTTCAGGACC & This work \\
\hline probe2-R & & CGCCAACTCCCATGTCTGTTAGAGA & This work \\
\hline \multicolumn{4}{|c|}{ BAHD1 KO mice - Genotyping } \\
\hline Name & Position & Sequence & Reference \\
\hline 4582 & Ef & TACCCTGCAGGCAGGTTCTCCG & This work \\
\hline 5488 & Ef & GCAGCACTCCTCAGACTGGCAGG & This work \\
\hline 4583 & $\mathrm{Er}$ & TGGCCAAGCTAGTGCTGGCAACC & This work \\
\hline 4584 & $\mathrm{Er}$ & CCCACACCACAAACGGAGTGCC & This work \\
\hline 255 & $\mathrm{Nf}$ & AATGCCTGCTCTTTACTGAAGGCTC & This work \\
\hline 4587 & Lxr & GAAGTTATACTAGAGCGGCC & This work \\
\hline 548 & $\mathrm{Nr}$ & CCAGACTGCCTTGGGAAAAG & This work \\
\hline 4585 & Wf & GTGTGTGTCGATCCTGGTTTCC & This work \\
\hline 4586 & $\mathrm{Wr}$ & AGTGTGTGTCATGGAATCCCTC & This work \\
\hline
\end{tabular}


Table S6. PCR products and digests for the validation of BAHD1+/- mice.

\section{(A) Digestions used to validate the 5 ' and 3 ' insertion}

Four different digests were used to validate correct homologous recombination events. Two digests validate the 5 ' insertion, 3 other digests validate the 3 ' insertion.

\begin{tabular}{cllcc}
\hline Probe & Digest & Enzyme & WT allele (kb) & Targeted Allele (kb) \\
\hline \multirow{2}{*}{ Neo } & 5'-first & AflII & - & 11.8 \\
(probe1) & 5'-second & EcoRV & - & 8.9 \\
& 3'-first & AccI & - & 7.5 \\
& 3'-second & BlpI & - & 9.2 \\
& 3'-third & Bst $\mathrm{BI}$ & - & 21.4 \\
\hline
\end{tabular}

(B) Digestions used to validate with external probe

\begin{tabular}{cllcc}
\hline Probe & Digest & Enzyme & WT allele (kb) & Targeted Allele (kb) \\
\hline \multirow{2}{*}{ 5' external } & first & ApaI & 15.5 & 11.6 \\
(probe2) & second & HpaI & 15.5 & 8.5 \\
& third & EcoRI & 6.8 & 11.0 \\
\hline
\end{tabular}

(C) PCR fragments for genotyping (expected size in bp)

\begin{tabular}{lclccc}
\hline Region analyzed & Primers & $\begin{array}{c}\text { Position } \\
\text { (fig. S10) }\end{array}$ & WT allele & $\begin{array}{c}\text { Targeted } \\
\text { allele (L2) }\end{array}$ & $\begin{array}{c}\text { KO allele } \\
\text { (L-) }\end{array}$ \\
\hline $\begin{array}{l}\text { WT allele specific PCR } \\
\text { (5' part of the targeted locus) }\end{array}$ & $4582-4586$ & $\mathrm{Ef} / \mathrm{Wr}$ & 497 & $\dagger$ & $\dagger$ \\
$\begin{array}{l}\text { WT allele specific PCR } \\
\text { (3' part of the targeted locus) }\end{array}$ & $4585-4583$ & $\mathrm{Wf} / \mathrm{Er}$ & 433 & $\dagger$ & $\dagger$ \\
5' part of the Neo marker & $4582-548$ & $\mathrm{Ef} / \mathrm{Nr}$ & $\dagger$ & 499 & $\dagger$ \\
3' part of the Neo marker & $255-4583$ & $\mathrm{Nf} / \mathrm{Er}$ & $\dagger$ & 453 & $\dagger$ \\
Excision of the Neo marker & $4582-4584$ & $\mathrm{Ef} / \mathrm{Er}$ & $9515^{*}$ & $2520^{*}$ & 851 \\
LoxP specific PCR & $4582-4587$ & $\mathrm{Ef} / \mathrm{Lxr}$ & $\dagger$ & 423 & 423 \\
\hline
\end{tabular}

* This PCR product was not observed using our PCR genotyping conditions.

$\dagger$ No Amplicon should be obtained. 
Table S7. Crystallography. Data collection, phasing and refinement statistics.

LntA structure data are deposited at the Worldwide Protein Data Bank (http://www.wwpdb.org/), ID \#2x14, structure factor file \#r2x14sf.

\section{Data collection}

\section{Data set}

Wavelength $(\AA)$

Space group

$\mathrm{a}(\AA)$

$\mathrm{b}(\AA)$

c $(\AA)$

Resolution $(\AA)$ (last shell limits)

No. observed/unique reflections

Completeness (\%)

Rmeas (last shell)

Rmrgd-F (last shell)

$\mathrm{I} / \sigma(\mathrm{I})$ (last shell)
Se Met Peak

0.979

$\mathrm{P} 41212$

49.7

49.7

141.8

$2.3(2.4-2.3)$

$223,287 / 14,639$

96.7 (91.4)

8.4 (51.8)

$5.4(23.2)$

$27.45(8.3)$

\section{Phasing}

Phasing power ano

2.620

FOMobs

0.1062

FOMDM

0.5063

\begin{tabular}{ll}
\hline Refinement & \\
\hline Resolution $(\AA)$ & 2.3 \\
Rwork (\%) & 23.22 \\
Rfree (\%) & 25.52 \\
No. of protein atoms & 1,210 \\
No. of solvent atoms & 41 \\
RMS deviation, bond lengths $(\AA)$ & 0.02 \\
RMS deviation, bond angles $\left({ }^{\circ}\right)$ & 1.972 \\
Mean B factor $(\AA 2)$ & 39.26 \\
Residues in most favored/allowed/outlier region of Ramachandran plot & $136 / 6 / 0(142)$ \\
(total) & \\
\hline
\end{tabular}




\section{References}

1. P. Glaser et al., Science 294, 849 (Oct 26, 2001).

2. A. Miyawaki, R. Y. Tsien, Meth Enzymol 327, 472 (Jan 1, 2000).

3. S. Dramsi et al., Mol Microbiol 16, 251 (Apr 1, 1995).

4. P. Lauer, M. Y. N. Chow, M. J. Loessner, D. A. Portnoy, R. Calendar, J Bacteriol 184, 4177 (Aug 1, 2002).

5. E. Derivery et al., Dev Cell 17, 712 (Nov, 2009).

6. H. Bierne et al., Proc Natl Acad Sci U S A 106, 13826 (Aug 18, 2009).

7. $\quad$ E. Derivery, A. Gautreau, Methods Enzymol 484, 677 (2010).

8. E. Gouin et al., Proc Natl Acad Sci US A 107, 17333 (Oct 5, 2010).

9. $\quad$ P. Steffen et al., Cell Motil Cytoskeleton 45, 58 (Jan 1, 2000).

10. D. Ribet et al., Nature 464, 1192 (Apr 22, 2010).

11. H. M. Cooper, Y. Paterson, Curr Protoc Immunol Chapter 2, Unit 2.4 (May 1, 2001).

12. M. Fromont-Racine, J. C. Rain, P. Legrain, Nat Genet 16, 277 (Jul 1, 1997).

13. E. Formstecher et al., Genome Res 15, 376 (Mar 1, 2005).

14. S. F. Altschul et al., Nucleic Acids Res 25, 3389 (Sep 1, 1997).

15. H. Bierne et al., J Cell Sci 118, 1537 (Apr 1, 2005).

16. J. Pizarro-Cerda, M. Lecuit, P. Cossart, in Molecular Cellular Microbiology. (Academic Press Inc, San Diego, 2002), vol. 31, pp. 161-177.

17. R. Jonquières, H. Bierne, F. Fiedler, P. Gounon, P. Cossart, Mol Microbiol 34, 902 (Dec 1, 1999).

18. H. Boukarabila et al., Genes Dev 23, 1195 (May 15, 2009).

19. C. Cheers, I. F. McKenzie, Infect Immun 19, 755 (Mar, 1978).

20. A. Camejo et al., PLoS Pathog 5, e1000449 (May 1, 2009).

21. U. K. Laemmli, Nature 227, 680 (Aug 15, 1970).

22. W. Kabsch, Acta Crystallogr D Biol Crystallogr 66, 125 (Feb 1, 2010).

23. G. Bricogne, C. Vonrhein, C. Flensburg, M. Schiltz, W. Paciorek, Acta Crystallogr D Biol Crystallogr 59, 2023 (Nov 1, 2003).

24. E. de La Fortelle, G. Bricogne, Charles W. Carter, Jr., in Methods in Enzymology. (Academic Press, 1997), vol. Volume 276, pp. 472-494.

25. P. Emsley, K. Cowtan, Acta Crystallogr D Biol Crystallogr 60, 2126 (Dec 1, 2004).

26. A. Perrakis, R. Morris, V. S. Lamzin, Nat Struct Biol 6, 458 (May 1, 1999).

27. G. N. Murshudov, A. A. Vagin, E. J. Dodson, Acta Crystallogr D Biol Crystallogr 53, 240 (May 1, 1997).

28. L. Fritsch et al., Mol Cell 37, 46 (Jan 15, 2010).

29. C. Sabet, M. Lecuit, D. Cabanes, P. Cossart, H. Bierne, Infect Immun 73, 6912 (Oct 1, 2005).

30. M. Lavigne et al., PLoS Genet 5, e1000769 (Dec, 2009).

31. S. Stockinger, T. Decker, Immunobiology 213, 889 (2008).

32. L. A. Zenewicz, H. Shen, Microbes Infect 9, 1208 (Aug, 2007).

33. C. Sommereyns, S. Paul, P. Staeheli, T. Michiels, PLoS Pathog 4, e1000017 (Mar, 2008).

34. M. Mordstein et al., J Virol 84, 5670 (Jun, 2010).

35. M. Trost et al., Proteomics 5, 1544 (Apr, 2005).

36. H. Bierne, P. Cossart, Microbiol Mol Biol Rev 71, 377 (Jun, 2007).

37. N. E. Freitag, G. C. Port, M. D. Miner, Nat Rev Microbiol 7, 623 (Sep, 2009).

38. R. D. Sleator, D. Watson, C. Hill, C. G. Gahan, Microbiology 155, 2463 (Aug, 2009).

39. C. Sabet et al., Infect Immun 76, 1368 (Apr, 2008). 
40. P. Mandin, F. Repoila, M. Vergassola, T. Geissmann, P. Cossart, Nucleic Acids Res 35, 962 (Jan 1, 2007).

41. D. Balestrino et al., Appl Environ Microbiol, (Apr 2, 2010). 